\title{
THE ECONOMIC RISKS \\ OF INTERMODAL CONTAINERISATION BY 1988
}

A Research in Risk Management and Technological Forecasting * by Jacques P. Pezier, Donald C. Creswell, and Stanley J. Davenport

(SRI - Stanford Research Institute)

\section{CONTENTS}

1. OVERVIEW 7

1.1 Introduction 7

1.2 Objectives and Scope of the Study 8

1.3 Summary of Findings and Conclusions 9

2. THE DEVELOPMENT OF INTERMODAL CONTAINERISATION 18

2.1 Historical Development 18

2.2 The Future of Containerisation to $1988 \quad 22$

2.3 Relevant Trends in the Evolution of Containerisation and Con-
tainerised Trade

3. EVALUATION OF ECONOMIC RISKS ASSOCIATED WITH CONTAINERISATION 30

3.1 Risks to Containers and Equipments 30

3.2 Risks to Cargo and Indirect Damages 35

4. REFLECTIONS ON RISK PREVENTION AND CONTROL 44 APPENDICES :
A Glossary
B Containerised Cargo Losses Statistics 49
C List of Panel Members $\quad 53$
D Short Bibliography $\quad 55$

* Research sponsored by "The Geneva Association". 


\section{Overview}

\subsection{Introduction}

Economic development since the most ancient times has been closely associated with the development of trade and therefore with progress in transport technology. Recent history indicates that the availability of efficient transport systems may in fact be more important than ever for the material welfare of peoples as measured by traditional economic indices. For example, thus far in the twentieth century the growth in transport volume (measured in tons $X \mathrm{~km}$ ) within all developed countries has been highly correlated to the growth in gross national product and generally larger than the latter. The development of modern transport systems is also often dictated by other than purely economic objectives such as strategic, cultural or even prestige goals. As a whole, investments in transport systems represent now between 20 and $25 \%$ of all investments in most developed countries and many emerging countries have judged it useful to make even more considerable efforts in relative terms in order to avail themselves of the latest, often most capital intensive, transport technologies.

Among recent advances in transport technology, the concept of the box or container must rival in simplicity and pervasiveness with the concept of the wheel. Like the wheel, the box offers clear advantages when integrated into a system designed around it. A container is simply a large, robust and reusable box designed for ease of transshipment and intermodal utilisation. The full advantages of containerised transport are achieved only when containers are used in conjunction with specially designed ships, handling equipments, marine and inland terminals, railway cars, trailers, etc.

Early attempts to containerise freight were mitigated successes because one or several elements of the complete system were missing. For example, since the end of the last century railways in Europe, the U.S. and Japan have used standard size containers on railway cars. However, these boxes could not be easily transported from wagons to lorries, barges or ships and thus their use was limited to one transportation mode. Likewise, the Conex Box used by American Forces during the Korean War moved almost exclusively on a pier-to-pier intramodal basis.

The real break-through came in 1956 when a U.S. road haulier expanded into coastal sea transport and, to reduce the cost of cargo handling and transshipments, sent by ship between New York and Houston 30 trailer type boxes. The experiment proved successful and new standardised equipment was designed including 35 foot containers and special containerships with slotted holds. In 1961 this company reincorporated as 
Sea-Land Service Inc. and started a U.S. intercoastal service. In 1966 containers were introduced on the North Atlantic route and the Far East route between the U.S. West Coast, Japan and then the Philippines.

During the next five years large scale containerisation expanded to all major deep sea routes. Shipowners and port authorities took the calculated risk of investing in new costly equipments based on the anticipated benefits of container traffic. Most of these benefits have materialised. Significant savings have resulted for both Combined Transport Operators (CTO) and shippers. Ease of transshipment, greater automation and simplified packaging lead to better equipment utilisation and reduced operating costs. Shippers not only benefit from reduced transport prices but also from speedier and safer delivery.

It would be wrong, however, to assume that present container technology is the final answer to all intermodal transport problems in all circumstances. Firstly, with the benefits of experience, containerised transport technology has rapidly evolved since the beginnings of large scale containerisation. For example, early containers were simply modified road trailer boxes which suffered rapid and extensive corrosion damages in the marine environment. New box designs are quite different and far more resistant to rough handling and the marine environment. Likewise, today's third generation containerships are about as different from first generation containerships as those were different from break bulk carriers. This technological evolution will continue if containerised transport is subject to critical economic analysis from a system point of view showing the benefit, costs and risks of alternative refinements.

Secondly, present container technology does not offer significant advantages over more traditional or new alternative methods for all commodities on all trade routes. Many commodities fall into a greyish area where present day containerisation offers advantages and disadvantages of comparable magnitudes: such may be the case, for example, for cocoa beans, crude rubber and some natural fibres. It is typical that several of these commodities are susceptible to various forms of spoilage whether they are put into containers or transported by alternative means. Economically rational decisions for the transport of these commodities should be based on a detailed understanding of the risks involved. Such understanding may lead to the development of new methods of conditioning, packaging, stuffing, etc. Beyond the tactical decision of shipping a particular commodity into a container or not, there are more strategic decisions about whether to open new container routes, the design, selection and upgrading of equipment and the definition of operational procedures. Such decisions should be based on comprehensive economic analyses taking into account the various levels of risks presented by alternative solutions.

\subsection{Objectives and scope of the study}

There is no doubt that the containerised system of transport has brought considerable improvements to intermodal transports in terms of lower costs, greater speed and improved reliability. As a consequence containerisation is still rapidly expanding despite the huge capital investments required. It remains, nonetheless, that containerisation has not eliminated all risks from intermodal transport. In fact, the absolute amount of losses and damages that will result from containerised transport over the coming decade is expected to be quite considerable but a detailed analysis of such risks is difficult. By its very nature containerised transport benefits from a high 
degree of automation and conceals the cargo from pick up to delivery unless deliberate, costly inspections are carried out in between. Many damages are therefore revealed only long after they took place and exact causes and locations of incidents are difficult to assess. The insurance industry possesses relevant information which suffers however from being partial, fragmented and outdated because of complex liability rules, limited coverages and the lag between loss experience and future loss potential in a rapidly evolving technology.

The purpose of this study was therefore to develop a comprehensive and prospective view on the likely evolution of economic risks associated with the use of containers as it can be projected over the next decade.

The major steps in this research were to :

1. estimate the future of containerisation to 1988 ;

2. identify and classify losses and damages resulting from container use and estimate these risks in probability and magnitude ;

3. reflect on the means of reducing these risks or protecting against them.

Two broad categories of losses and damages have been considered : those affecting the container itself and those affecting the containerised cargo. In both cases and particularly in the second, indirect damages were considered beyond the direct physical damages and losses.

The method of approach consisted of collating statistics and published information on container trade, container population and damages. From this basis forecasts were developed for the next ten years and submitted to the critical review of a panel of 36 experts. Experts were contacted first by questionnaire and their answers were then completed by a series of interviews in the U.S. and in Europe. The list of all experts contacted is given in Appendix C. The results presented thereafter represent, therefore, the best collective opinion of these experts.

\subsection{Summary of findings and conclusions}

\subsubsection{The future of intermodal containerisation}

The container "revolution" may be over, nonetheless container transport is expected to continue to develop at a brisk pace over the next decade and its form will evolve significantly : displacement of trade routes, shift in balance of freight, technological and operational changes, etc. All these modifications will have strong influences on the amounts and types of future risks.

It was therefore necessary to form a detailed opinion about the future of containerisation which could be used as a working hypothesis for forecasting risks. The general view about future volumes is reported in Table 1 and Figure 1.

Figures from 1973 to 1976 included can be considered as reliable measures. Figures from 1977 and 1978 are statistical estimates based on large samples but could be erroneous by up to $5 \%$. Figures beyond 1979 are educated guesses reflecting the general view of the members of the panel after discussions with the authors. There are great uncertainties about the 1988 estimates particularly about the amount of cargo (and yearly demand for new containers). An $80 \%$ uncertainty bracket for the container population is shown in Figure 1 (shaded area). 
Table 1

Growth of containerisation

\begin{tabular}{|c|c|c|c|c|c|c|c|c|}
\hline \multirow[t]{2}{*}{ Year } & \multicolumn{2}{|c|}{$\begin{array}{l}\text { Liner } \\
\text { Cargo }\end{array}$} & \multicolumn{2}{|c|}{$\begin{array}{c}\text { Containerised } \\
\text { Cargo }\end{array}$} & $\begin{array}{c}\text { Container } \\
\text { Traffic }\end{array}$ & \multicolumn{2}{|c|}{$\begin{array}{l}\text { Container } \\
\text { Population }\end{array}$} & \multirow{2}{*}{$\begin{array}{c}\text { New } \\
\text { Container } \\
\text { mTEU }\end{array}$} \\
\hline & $m T^{a}$ & $\operatorname{lnd}^{b}$ & $m T$ & Ind & $m T E U^{c}$ Ind & mTEU & Ind & \\
\hline 1973 & 200 & 100 & 51 & 100 & 14.2100 & 0.99 & 100 & 210 \\
\hline 1974 & 215 & 108 & 58 & 114 & 16.2114 & 1.20 & 121 & 230 \\
\hline 1975 & 205 & 103 & 58 & 114 & $17.1 \quad 120$ & 1.40 & 141 & 180 \\
\hline 1976 & 248 & 124 & 59 & 135 & $20.3 \quad 143$ & 1.58 & 160 & 230 \\
\hline 1977 & 266 & 133 & 76 & 149 & $22.5 \quad 158$ & 1.86 & 188 & 360 \\
\hline 1978 & 286 & 143 & 83 & 163 & $25.0 \quad 176$ & 2.20 & 222 & 400 \\
\hline 1979 & 300 & 150 & 89 & 175 & $27.0 \quad 190$ & 2.42 & 244 & 320 \\
\hline 1980 & 320 & 160 & 96 & 188 & $29.5 \quad 208$ & 2.70 & 275 & 360 \\
\hline 1981 & 343 & 172 & 103 & 202 & 32.1226 & 2.95 & 298 & 370 \\
\hline 1982 & 367 & 184 & 110 & 216 & $34.7 \quad 244$ & 3.22 & 325 & 410 \\
\hline 1983 & 390 & 195 & 117 & 229 & $37.4 \quad 263$ & 3.52 & 356 & 450 \\
\hline 1984 & 417 & 209 & 125 & 245 & $40.3 \quad 284$ & 3.85 & 389 & 510 \\
\hline 1985 & 443 & 222 & 133 & 261 & 43.4306 & 4.20 & 424 & 540 \\
\hline 1986 & 470 & 235 & 141 & 276 & 46.7329 & 4.57 & 462 & 570 \\
\hline 1987 & 497 & 249 & 149 & 292 & 50.2354 & 4.97 & 502 & 590 \\
\hline 1988 & 530 & 265 & 159 & 312 & $54.0 \quad 380$ & 5.40 & 545 & 630 \\
\hline $\begin{array}{l}\text { Projected } \\
\text { Growth } \\
\text { from } 1978 \\
(\%)\end{array}$ & 6. & & & 5.7 & 8.0 & & 9.4 & \\
\hline $\begin{array}{l}\text { Historical } \\
\text { Growth } \\
1973-78 \\
(\%)\end{array}$ & 7. & .4 & & 0.2 & 12.0 & & 7.3 & \\
\hline $\begin{array}{r}a \mathrm{mT} \\
b \text { Figu } \\
\text { comparison } \\
c \mathrm{mTE}\end{array}$ & $\begin{array}{l}\text { millior } \\
\text { in } \\
\text { of gro } \\
=\text { mil }\end{array}$ & $\begin{array}{l}\text { ns of } \mathrm{r} \\
\text { italics a } \\
\text { owths. } \\
\text { illions o }\end{array}$ & $\begin{array}{l}\text { ric tons } \\
\text { percen } \\
\text { Wenty }\end{array}$ & Foot $\mathrm{Co}$ & $\begin{array}{l}1973 \text { values that } \\
\text { ntainer Equivalen }\end{array}$ & $\begin{array}{l}\text { have be } \\
\text { Unit. }\end{array}$ & een ac & to facilitate \\
\hline
\end{tabular}


Figure 1

Growth of container transport

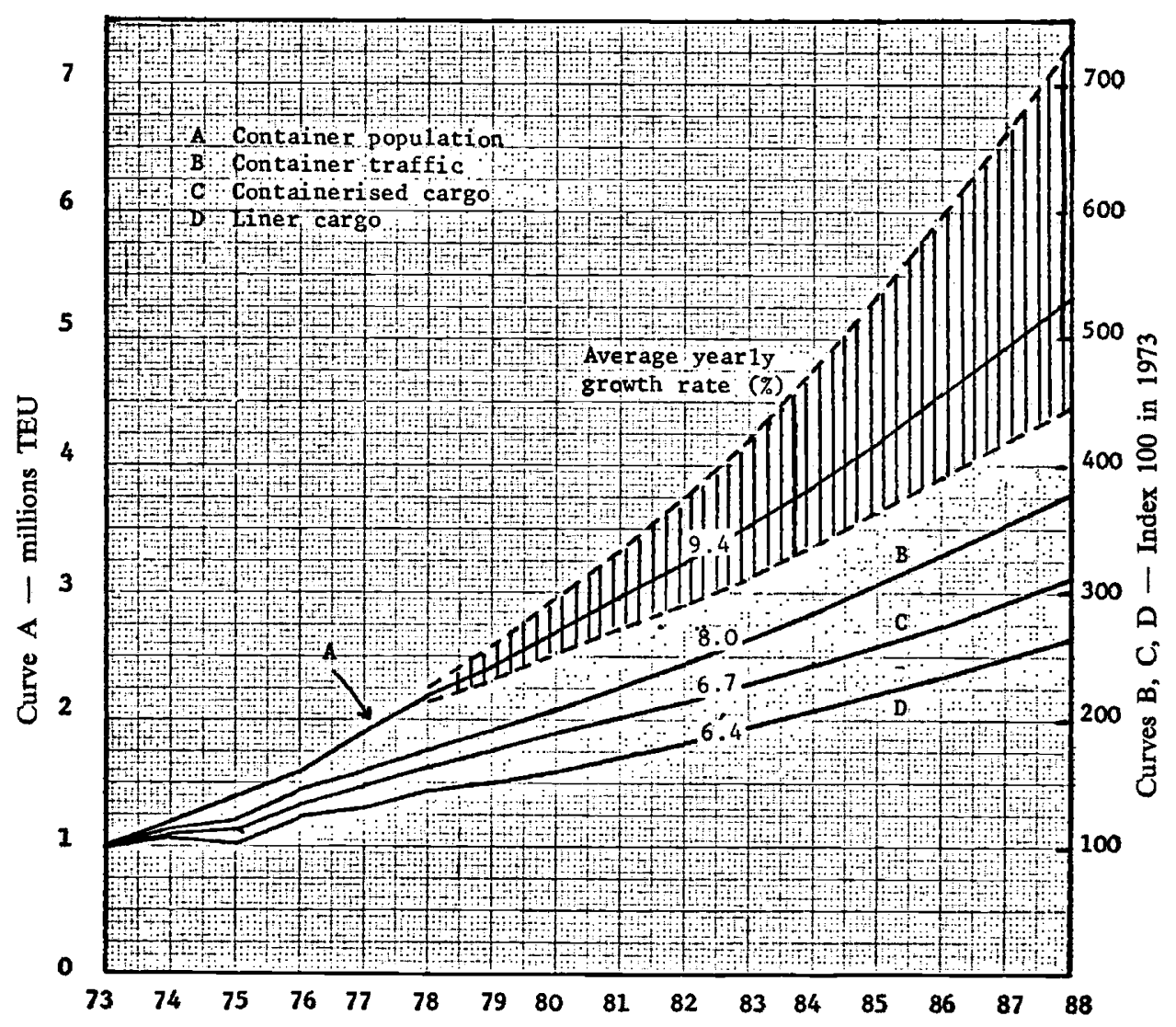


The volume forecasts call for the following comments :

1. The future growth of trade in weight over the next decade is foreseen as significantly lower than the historical average over the past decade. However, general cargo (mostly manufactured and semi-manufactured goods) will still grow at about $5.7 \%$ per year, $1 \%$ per year faster than bulk commodities.

2. Liner cargo will continue to represent an ever increasing part of general cargo : $30 \%$ in $1973,32.5 \%$ in 1978 and close to $35 \%$ in 1988.

3. Containerised cargo which consists mainly of high value manufactured goods, consumer goods, foodstuffs and perishables has in the past developed faster then liner cargo : $25 \%$ of liner cargo in 1973, $29 \%$ in 1978. However, the potential for containerisation of goods will be reaching its limit and will stabilise toward $31 \%$ of liner cargo by the mid-eighties. Container cargo in weight is therefore likely to increase at an average of about $6.7 \%$ per year over the coming decade. An $80 \%$ confidence interval would go from $5 \%$ to $10 \%$ per year.

4. Containerised trade will become more unbalanced as new, more marginal routes are open. Full container movements will therefore continue to be a decreasing fraction of all container movements : $86 \%$ in 1973, $79 \%$ in 1978 , and $70 \%$ in 1988. Consequently, container traffic (measured in movements of Twenty Foot Container Equivalent Units, TEU) is likely to grow at an average of about $80 \%$ per year.

5. Further, the average number of round trips (between shipper and receiver) per container per year which was 3.58 in 1973 and only 2.84 on 1978 will continue to decrease and reach about 2.5 in 1988. Because new deep sea route are longer, inland transport of containers increases in relative importance and less intensive uses of containers are appearing (e.g. temporary warehousing). The container population is therefore likely to grow at an average of $9 \%$ to $10 \%$ per year until 1988. An $80 \%$ confidence interval would range from $7.7 \%$ to $12.5 \%$ per year. In addition the next three years will see a container surplus because of production overcapacity.

In summary, over the next decade containerised cargo, in weight, will not quite double but due to changes in the use of containers, container traffic and the container population are very likely to more than double.

Major anticipated changes in the structure and operations of container transport are as follows :

1. Containers - greater standardisation of containers (more $20^{\prime}$ and $40^{\prime}$ containers $8^{\prime} 6^{\prime \prime}$ high) and upgrading of structural resistance as well as improved protection against corrosion. On the other hand, the average age of the container population will increase by $50 \%$.

2. Ownership - up to $2 / 3$ of all containers owned by leasing companies (even a greater proportion for $20^{\prime}$ steel containers) as opposed to $39 \%$ in 1978.

3. Repair and Maintenance - general improvement due to enforcement of international conventions (CSC), greater awareness of shippers, owner and insurers and better control and repair facilities (facilitated by greater size of international owners). 
4. Other equipments - gains in efficiency and safety from continued technological advances in the design of modern containerships, transshipments equipment, control systems, etc., will probably be more than counterbalanced by the rapid expansion of trade to places with inferior handling and transport facilities.

5. Trade routes and modes of transport - the traditional deep sea routes will lose in importance to : new deep sea routes (many to the southern hemisphere) ; a rapid expansion of feeder service and inland transportation corresponding to a greater demand for door-to-door services; the substitution of land bridges (e.g. transsiberian, transcaucasian) to sea routes.

6. Commodities - a higher proportion of high value consumer goods including perishables will be containerised. More perishables, in particular, will be carried in containers across the equator leading to a greater exposure to some types of risks (e.g. condensation).

\subsubsection{Anticipated economic risks}

The principal risks specifically associated with container transport can be conveniently classified into two broad categories : (1) damages and losses of containers and associated equipment, (2) damages and losses of cargo as well as loss of life, injury and consequential losses to combined transport operators and shippers associated with the use of containers. In what follows, we shall not be concerned directly with legal, regulatory and insurance aspects of liability assignment and compensation of damages. Rather we take a comprehensive and prospective view of all economic risks directly and indirectly affecting all parties involved with container transport.

A. Risks to containers and equipments

The study concentrated on damages to containers for the following reasons :

- losses of ships are too rare to draw significant conclusions as to the relative risks presented by containerships as opposed to conventional dry bulk ships except to underline the higher value of containerships. Also due to the variety in designs and modes of operation each ship must be considered a special case. Minor damages to ships are not significant compared to damages to containers;

- damages to handling and transport equipment other than ships are also small compared to damages to containers except in the case of straddle carriers where a number of accidents (usually due to poor visibility, coupled with human error) have been recorded.

\section{(a) Total container damages and losses; frequency and magnitude}

Total container damages and losses in 1988 exclusive of maintenance costs will amount to about 1.5 billion U.S. dollars (end 1978) of which $77 \%$ are direct repair costs, $4 \%$ are losses and $19 \%$ are business opportunity losses due to unavailability of the container.

This is almost four times the corresponding 1978 figure of about $\$ 400 \mathrm{~m}$. The main causes of this increase are :

- rapid increase of container population $(+145 \%)$;

- increase in relative cost of repairs $(+16 \%)$; 
- increase in frequency of damages due to greater exposure in feeder services, inland transport and trade with less developed countries $(+14 \%)$;

- increase in both frequency and cost of repairs due to $50 \%$ older container population and new safety conventions $(+10 \%)$;

- relative increase in cost of repairs due to greater proportion of steel containers $(+5 \%)$.

Repairs will average $\$ 215$ per TEU per year (slightly less for $40^{\prime}$ containers and more for $20^{\prime}$ containers) with an average frequency of about 1.2 per TEU per year and a cost per repair of $\$ 180$.

Total losses will be of the order of $0.5 \%$ per container per year at an average cost of $\$ 2000$ per used container but usually a large number of containers are simultaneously lost (ship collision, ship sinking, train derailment).

(b) Container damages and losses by location

$\begin{array}{ll}\text { Terminals } & 60 \% \\ \text { Road } & 15 \% \\ \text { Rail } & 15 \% \\ \text { Sea } & 10 \% \\ \text { Air } & -\end{array}$

This is believed to represent a larger proportion of losses in terminals and on the road than todays' reflecting increase in door-to-door services necessitating more handlings, inland terminals and road transport. Rail is expected to become safer despite an increase in relative volume. Deep sea transport continues to become safer but the increase in short sea feeder services neutralises this effect.

(c) Container damages by types

$\begin{array}{ll}\text { Roof } & 30 \% \\ \text { Sides } & 15 \% \\ \text { Doors (and end wall) } & 15 \% \\ \text { Floor } & 15 \% \\ \text { Other } & 25 \%\end{array}$

The roof remains the weak point of most containers especially aluminium clad containers and suffers greater exposure due to more frequent handlings. Damage to doors become more frequent than at present due to the larger place taken by road and rail transport. The "other" category consists mostly of damages to the container frame.

(d) Container damages and losses by cause

$\begin{array}{ll}\begin{array}{l}\text { Rough handling } \\ \text { Poor stowage of cargo }\end{array} & 50 \% \\ \quad \text { and lashing of container } & 25 \% \\ \text { Excessive transport } & \\ \quad \text { stresses including adverse } & \\ \quad \text { weather conditions } & 10 \% \\ \text { Accident to carrier } & 10 \% \\ \begin{array}{l}\text { Other including } \\ \quad \text { structural weaknesses }\end{array} & 5 \%\end{array}$


This classification is the most subjective but nonetheless clearly points out rough handling and poor stowage as the two major causes of damages and losses. Interestingly, these two types of causes should be among the easiest to control.

B. Risks to cargo and indirect damages

The following estimates are educated guesses and many are highly subjective. They encompass losses and damages to cargo as well as consequential losses to business whether or not such risks are currently covered by insurance. However, loss of life and bodily injury resulting from container transport are not included for reasons developed in Section 3.2.

\section{(a) Total cargo risks and indirect damages}

Total economic losses in 1988 will amount to about 1.2 billion U.S. dollars (end 1978) of which $77 \%$ are direct losses (cargo damages and losses, administrative costs of claims, etc.) and $23 \%$ are indirect losses (consequential losses to business). This is three times the corresponding $\$ 400 \mathrm{~m}$ estimated for 1978.1 The main reasons for this increase are :

- increase in container cargo $(+115 \%)$;

- increase in frequency of damages due to greater exposure of feeder services, inland transport and trade with less developed countries despite improvements in packaging of goods and stuffing of containers $(+20 \%)$;

- increase in average value of container cargo $(+8 \%)$;

- increase in consequential losses $(+8.3 \%)$.

Positive effects due to improvements in quality of equipments and maintenance procedures are expected to be counterbalanced by the negative effects of an older container population.

Damages, frequencies and magnitudes are very much dependent upon the types of damages and are discussed under that heading.

\section{(b) Cargo damages and losses by location}

This is difficult to estimate because of the large proportion of damages concealed until inspection by the receiver. Location should not be interpreted as a direct cause ; it simply helps to understand future risks depending on the development of each mode of transport :

$\begin{array}{lr}\text { Terminals } & 45 \% \\ \text { Sea - deep } & 12 \% \\ \text { - feeder service } & 15 \% \\ \text { Road } & 12 \% \\ \text { Rail } & 15 \% \\ \text { Air } & 1 \%\end{array}$

Terminals, whether marine, rail, road or air, play a predominant role because of handling risks, theft opportunities and exposure to wheather (rain, typhoons, etc.).

1 It is noteworthy that the estimate for cargo damages and losses in 1978 is equal to the estimate for container losses and damages although the value of the cargo is several times higher than the value of the container (typically 4-12 times higher for fully loaded containers). 
The sea leg poses greater risks to the cargo than to the box because many hazards (sea water, excess of temperature, condensation) affect the cargo but not so much the box. The above percentages indicate total risks per location and therefore take into account the relative volume of container transport for each mode.

(c) Cargo damages, losses and delays by type

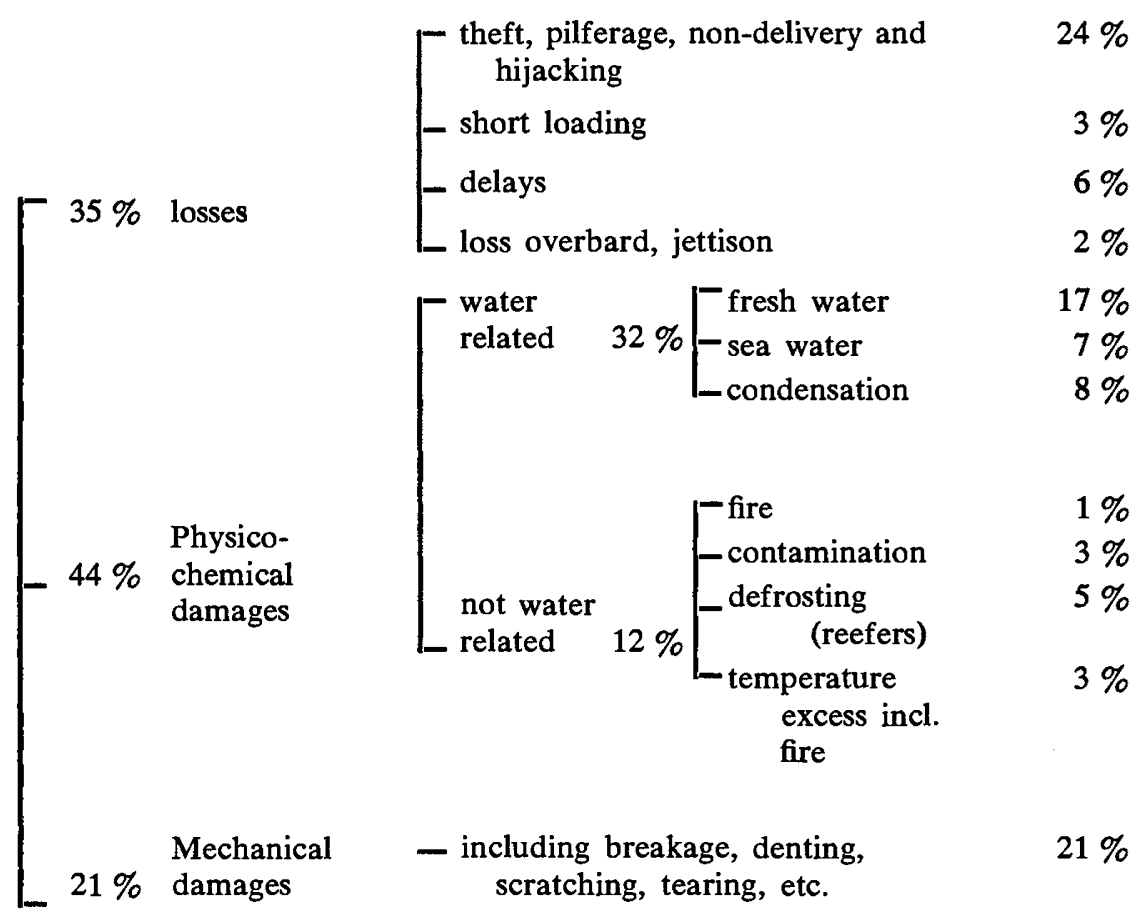

The above distribution is believed to show relatively increased risks compared to the present in the following categories : delays, fresh water, condensation, temperature excesses and mechanical. On the other hand, a decrease is expected in the categories of short loading, loss overboard, sea water and contamination.

The average magnitude and frequency of risks depends upon the type. To a large extent the number of claims following a given accident also depends on legal conventions (limits of liability, definition of a package, etc.) which are progressively changing. The following numbers have therefore more value in relative than absolute terms.

Type

Theft

Pilferage, non-delivery

Short loading
Average Amount

360

160

520
Frequency

(per 1000 TEU

per year) 
Delay

Loss overboard $\quad 4000$

Fresh water

Sea water

Condensation

Fire

Contamination

Defrosting

Temperature excess

Mechanical

All Categories 2

(d) Cargo damages and losses by cause

Again this classification is subjective because causality can rarely be uniquely ascertained : for example, a breakage can be interpreted as caused by insufficient packaging or by rough handling; sweat may be attributed to weather extremes or improper ventilation. Assigned causes are :

$\begin{array}{ll}\text { Malicious acts } & 27 \% \\ \text { Bad packaging } & \\ \quad \text { stuffing \& stowage } & 23 \% \\ \text { Faulty containers } & 20 \% \\ \text { Rough handling } & 18 \% \\ \begin{array}{l}\text { Others (including accidents } \\ \quad \text { to carriers and acts of God }\end{array} & 12 \%\end{array}$

This classification should be useful in evaluating loss prevention and control measures.

\subsubsection{Reflections on risk prevention and control}

The foregoing findings should not be interpreted as having universal validity for all container transport. Indeed, there are and will be enormous differences of experience among trade routes, carriers, shippers and type of commodities. Nonetheless, there are clear trends which indicate where attention and efforts could be well spent :

- More than $50 \%$ of all risks are found in terminals (marine, inland and air terminals). The largest part $(36 \%)$ of these are due to rough handling causing damages to containers $(28 \%)$ and cargo $(8 \%)$. The rest is mostly theft of cargo $(9 \%)$.

- A second major category of risk (almost $25 \%$ ) can be traced to insufficient packaging or improper stowage and securing of goods and containers. This causes damages to cargo as well as to containers not only during handling but during intermodal transportation.

2 The frequency of claims for all categories is obtained by adding the frequencies of each category. The average amount of claims, namely 300 dollars, is equal to the sum of the average amounts of the various categories weighted by their relative frequencies. 
Terminal risks call clearly for greater attention to terminal operations and security measures. Among subjects worth studying further are :

- A comparison of facilities, operating procedures and loss experience of terminals attention should be given not only to the major marine terminal facilities where handling is normally efficient but also to the growing number of inland terminals (rail and road depots and air terminals) where equipments and handling procedures are often of lower standard as well as to smaller, often congested, port facilities in lesser developed countries.

- A review and analysis of inspection and repair facilities with a view to assessing economically viable rules for inspection, repair and maintenance.

- A review and analysis of terminal security with emphasis on physical protection, sealing procedures, control systems and documentation, customs clearance and inspection procedures.

Improvements in packaging and stowage require continuous research, information and training. Several organisations pursue research in packaging and are coordinated internationally ${ }^{3}$; a number of excellent information pamphlets have been published. It would be useful however to help shippers make rational decisions to develop a wide data base comparing the cost and risks associated with various forms of packaging and methods of transport for specific trade routes and commodities. This issue is indeed complex and goes well beyond the cost and risks of transport and into product design and choice of distribution methods.

Finally, it has been noted in the course of this study that information on containerisation risks (in particular, as compared with the risks of alternative methods of transport) is highly fragmented and often incomplete. The best information available comes from competent combined transport operators, leasing companies and shippers but it is by nature limited to their particular activities and conventionally defined liabilities. It is therefore difficult to generalise and extrapolate from such information. Claim statistics from insurers are often difficult to analyse (see Appendix B) and almost impossible to relate to the corresponding volume and type of containerised trade which often remains unknown to insurers. However, better information bases will become more valuable to insurers, shippers and carriers as the differences in experience between the most efficient and the less sophisticated container operations widens.

\section{The development of intermodal containerisation}

\subsection{Historical development}

In assessing the future growth of containerisation and the world population of containers, it is useful to review past trends in :

- the development of world dry cargo trade ;

- types of commodities included in dry bulk and general cargo ;

3 International Association of Packaging Research Institutes (IAPRI), Leatherhead, Surrey, U.K. 
- development of world general, liner and containerised cargo ;

- development of world containerised traffic, container population and round trips per twenty foot container equivalent units (TEU).

The tables and discussions that follow address each of these areas.

2.1.1 Development of world international dry cargo trade

Table 2 shows trends in dry cargo, bulk commodities and general cargo international trade from 1968 to 1978 . The growth rates over the ten year period have averaged $5.8 \%$ for dry cargo, $5.1 \%$ for bulk commodities and $6.2 \%$ for general cargo.

It should be noted that the historical growth rate for the general cargo component is greater than that for the bulk commodities component. The reason for this is that general cargo is made of manufactured and semi-manufactured goods as opposed to raw materials and becomes relatively more important with the development of world economic activity.

Table 2

Development of world international dry cargo trade

(millions of metric tons)

\begin{tabular}{|c|c|c|c|}
\hline Year & $\begin{array}{c}\text { Total } \\
\text { Dry Cargo } a\end{array}$ & $\begin{array}{c}\text { Bulk } \\
\text { Commodities }\end{array}$ & $\begin{array}{c}\text { General } \\
\text { Cargo }\end{array}$ \\
\hline 1968 & 930 & 448 & 482 \\
\hline 1969 & 990 & 484 & 506 \\
\hline 1970 & 1,100 & 505 & 605 \\
\hline 1971 & 1,120 & 572 & 548 \\
\hline 1972 & 1,180 & 593 & 587 \\
\hline 1973 & 1,350 & 691 & 659 \\
\hline 1974 & 1,450 & 739 & 711 \\
\hline 1975 & 1,380 & 698 & 682 \\
\hline 1976 & 1,540 & 713 & 827 \\
\hline 1977 (E) & 1,570 & 727 & 843 \\
\hline $1978(\mathrm{E})$ & 1,630 & 740 & 881 \\
\hline \multicolumn{4}{|l|}{ Growth } \\
\hline Rate \% & 5.8 & 5.1 & 6.2 \\
\hline
\end{tabular}

2.1.2 Commodities included in dry bulk and general cargo categories

Table 3 shows those commodities that are generally included in "dry bulk" and "general cargo" categories. When considering the potential for containerisation, it is

$\mathbf{E}=$ Estimated.

a Maritime Transport 1977, OECD, Paris, France, 1978.

b World Bulk Trades, Fearnley \& Egers Chartering Co., Ltd., Oslo, Norway, 1971-1976 (Combined and Bulk Carriers Over 18,000 DWT). 
necessary to clearly understand the differences between these two major categories. For the most part, dry bulk cargo is not potentially containerisable.

Dry bulk commodities consist mainly of raw materials and crude products, while general cargo commodities consist of manufactured and semi-manufactured goods (including liner cargo) plus small parcels of dry bulk cargo.

Table 3

Commodities included in dry bulk and general cargo categories

\begin{tabular}{lll}
\multicolumn{1}{c}{ Dry Bulk Cargo } & & \multicolumn{1}{c}{ General Cargo } \\
\cline { 1 - 1 } $\begin{array}{ll}\text { Coal, Manganese, and } \\
\text { Non-Ferrous Ores }\end{array}$ & & Liner Cargo \\
Bauxite and Alumina & & Wumber \\
Coal and Petroleum Coke & & Woodpulp \\
Scrap & & Animal Feedstocks \\
Phosphate Rock & Fertilizers \\
Gypsum & Iron and Steel \\
Limestone & Automobiles and Trucks \\
Cement & Other Neo-Bulk \\
Salt & \\
Sulphur & \\
Grain & \\
Raw Sugar & \\
Tapioca &
\end{tabular}

2.1.3 Development of world international general, liner and containerised cargo

Table 4 shows the trend in general, liner and containerised cargo between 1973 and 1978. The growth of liner cargo, at $7.4 \%$ per year average rate over the period vs $6.0 \%$ for general cargo is noteworthy, as is the growth rate in the average weight moving in containers which has grown at around $10.2 \%$ per year.

The increasing trend in the per cent of liner cargo moving in containers between 1973 and 1978 should be noted - about 4 percentage points during the five year period.

Table 4

Development of world international general, liner, and containerised cargo (millions of metric tons)

\begin{tabular}{|c|c|c|c|c|}
\hline Year & $\begin{array}{c}\text { General } \\
\text { Cargo }\end{array}$ & $\begin{array}{c}\text { Liner } \\
\text { Cargo }^{a}\end{array}$ & Weight & $\begin{array}{l}\text { Per cent of } \\
\text { Liner Cargo }\end{array}$ \\
\hline 1973 & 659 & 200 & 51 & 25 \\
\hline 1974 & 711 & 215 & 58 & 27 \\
\hline 1975 & 682 & 205 & 58 & 28 \\
\hline 1976 & 827 & 248 & 69 & 28 \\
\hline
\end{tabular}

a SRI International. 
Growth

Rate (\%)

7.4

10.2

2.1.4 Development of world containerised traffic, container population and round trips per TEU

Table 5 shows the growth rate in container traffic and container population between 1973 and 1978, as well as the round trips per TEU over the five year period.

Container Traffic - This statistic includes full and empty movements and is surrounded by a degree of uncertainty that will be addressed below. It should be noted that the historical growth rate for the container population is higher than that for container traffic. The reason for this is a reduction in the round trips per TEU (which fell from 3.58 in 1973 to 2.84 in 1978 according to our analysis).

The drop to 3.06 round trips per TEU in 1975, rising again to 3.20 in 1976 is due to an excess of containers in 1975, because although container traffic increased in 1975, its growth was substantially less than that of the container population.

A. Uncertainties associated with estimated container traffic

- Main transshipment ports commonly split their traffic statistics between direct and feeder containers. This is often not done by the feeder ports, thus causing an over-estimation of container traffic.

- Some 30 world container ports (including Los Angeles and Charleston) failed to supply any publishable TEU traffic data for 1977, thus causing an underestimation of container traffic.

These uncertainties tend to counteract each other, but it is difficult to determine the extent of this counteraction.

Table 5

Development of world containerised traffic, container population, and round trips per TEU

\begin{tabular}{lcccc} 
Year & $\begin{array}{c}\text { Traffic } \\
(1000 \text { TEUs })^{a}\end{array}$ & $\begin{array}{c}\text { Population } \\
(1000 \text { TEUs })\end{array}$ & & $\begin{array}{c}\text { Round Trips } \\
\text { per TEU }\end{array}$ \\
\cline { 5 - 5 } 1973 & 14,192 & & 991 & 3.58 \\
1974 & 16,246 & & 1,203 & 3.38 \\
1975 & 17,123 & & 1,398 & 3.06 \\
1976 & 20,260 & & 1,585 & 3.20 \\
1977 & 22,516 & & 1,861 & 3.02 \\
$1978(\mathrm{E})$ & 25,000 & & 2,200 &
\end{tabular}

Growth

Rate (\%)

12.0

17.3

$\mathrm{E}=$ Estimated

a Containerization International, December 1978 (includes empty container moves).

$b$ Containerisation Into the 1980's, Cargo Systems Research, Surrey, England, December 1978 (Mid-Year Estimates). 
B. Possible reasons for decrease in round trips per TEU

- Underestimates of container traffic.

- Growth of feedering.

- Surplus of containers (note 1975).

- Increases in lengths of trade routes (particularly to less developed areas where growth in containerised trade is considerably higher than in the industrialised world).

- Relative infrequence of sailings by operators to less developed areas.

- The large hinterland of some less developed countries (e.g. Iran, Nigeria), and poor internal transportation infrastructures.

- Use of containers for temporary storage in some less developed countries.

- Delays due to customs clearance and receipt of trade documents in less developed countries.

\subsection{The future of containerisation to 1988}

\subsubsection{Major uncertainties}

In the tables that follow, the outlook for the future of container traffic as well as the population of containers are developed. Prior to reading the projections, the uncertainties surrounding the projections should be noted. Experts of the panel were asked to indicate which, in their view, were the events that could have significant influence on the future of containerisation and its associated risks. Complete results were given in Table 6 . The three major events that would affect significantly the future volume of containerised trade are as follows :

- A slower world average economic growth than the $3 \%$ generally accepted as most likely. Every per cent change would create a 2 or even greater percentage change in the volume of containerised traffic. A higher than $3 \%$ average economic growth is seen as very unlikely.

- The widespread pressures for increased protectionism that are being felt in many countries. Examples include the tendency of the EEC to increase trade between member countries rather than from outside and the threat of import duties from the U.S.

- The extent to which, and when, liner trade form the major emerging areas (South America, West and East Africa, The Indian Sub-continent, Indonesia and China) will be containerised (a rapid expansion of container trade with these areas would increase risks even more significantly).

Also noteworthy for their influence on the future volume of containerised trade are :

- a massive Soviet expansion and the intervention of other outsiders (the Soviet Union is currently equipping far beyond its own needs); 
Table 6

Major factors that could affect the development

of containerisation and its associated risks

Factor

\section{POLITICAL}

1. Trade Restriction

2. Massive Soviet expansion and interventions of other outsiders

3. Opening of trade between U.S. and China

\section{REGULATORY}

4. Enforcement of container safety convention and conventions on dangerous commodities

5. Improved Customs clearance

6. New regulations for intermodal transport

\section{ECONOMIC}

7. Slower world economic growth (most likely is $3 \%$ )

8. Faster economic growth of some developing countries (Middle East, West Africa, South America)

9. Relative increase in shipments of consumer goods and perishables

10. Replacement of some traditional sea routes by land bridges

11. Expansion of feeder services and inland transport

\section{TECHNOLOGICAL}

12. Better training of personnel

13. Improvement of planning and control mechanisms

14. Better sealing systems

15. Upgrading of containers and equipment at terminal facilities

16. Higher standardisation

\section{SOCIAL}

17. Labour opposition

OTHER

18. Increase usage as temporary warehousing

19. Growth of alternative methods of transport

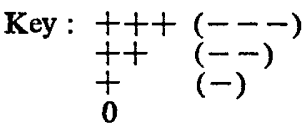

strong increase (decrease) marked increase (decrease) some increase (decrease) no significant change
Likelihood

Effects on

Volume Risk

medium

high

high

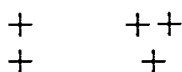

high

high

medium

medium

high

$+\quad++$

high

$0 \quad++$

high

high

$0 \quad+$

high

$+\quad+t$

high

high

?

medium

medium

$+\quad-$

medium

?

medium

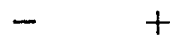

low 
- a further relative expansion of short sea feeder services and of inland services ;

- an upgrading of equipments and a lower price of new containers ;

- labour opposition to further automation;

- the growth of alternative and competitive methods of transport.

Because of these uncertainties, the projections that follow are shown with low and high ranges.

\subsubsection{World containerised traffic and container population 1979-1988}

Table 7 shows projections of container traffic and container population to 1988 .

Projections of container traffic are based on the historical relationships of growth in container traffic and growth in general cargo traffic and range from a low of $6.3 \%$ to a high of $11.1 \%$. However, the rate of growth is expected to be closer to the lower level (about $8 \%$ per year) rather than the higher level. The low and high bounds represent an approximately $80 \%$ confidence interval.

Projections of container traffic are more meaningful than projection of containerised tons because generally the container is volume limited rather than weight limited, that is, it is filled with cargo prior to reaching weight limits.

The container population, which grows from a low rate of $7.7 \%$ to a high of $12.5 \%$, is most likely to fall at around 9 to $10 \%$ per year. The high rates of growth are lower than historical rates of growth (of $17 \%$ ) due to relative saturation.

Table 7

Projections of world containerised traffic and container population

(thousands of TEUs)

Year

\begin{tabular}{l}
\hline \\
1979 \\
1980 \\
1981 \\
1982 \\
1983 \\
1984 \\
1985 \\
1986 \\
1987 \\
1988
\end{tabular}

Container Traffica

\begin{tabular}{|c|c|c|}
\hline Low & Medium & High \\
\hline 25,700 & 27,000 & 28,750 \\
\hline 27,500 & 29,500 & 32,650 \\
\hline 29,300 & 32,100 & 36,200 \\
\hline 31,200 & 34,700 & 40,450 \\
\hline 33,250 & 37,400 & 44,950 \\
\hline 35,350 & 40,300 & 49,950 \\
\hline 37,550 & 43,400 & 55,300 \\
\hline 39,800 & 46,700 & 61,150 \\
\hline 42,200 & 50,200 & 67,475 \\
\hline 44,700 & 54,000 & 74,350 \\
\hline
\end{tabular}

Container Population

\begin{tabular}{crrrr}
\hline Low & & Medium & & High \\
\cline { 1 - 1 } 2,300 & & 2,425 & & 2,575 \\
2,525 & & 2,700 & & 2,975 \\
2,700 & & 2,950 & & 3,325 \\
2,900 & & 3,225 & & 3,750 \\
3,125 & & 3,525 & & 4,225 \\
3,375 & & 3,850 & & 4,775 \\
3,625 & & 4,200 & & 5,350 \\
3,900 & & 4,575 & & 5,975 \\
4,175 & & 4,975 & & 6.675 \\
4,475 & & 5,400 & & 7,425
\end{tabular}

a Includes full and empty moves. 
Projected

Growth

Rate (\%)

6.3

8.0

11.1

7.7

9.3

12.5

Historical

Growth

Rate $(\%) b$

Container population was computed as follows :

(Container Traffic/4) / (Estimated Round Trips per TEU/year)

It was assumed that round trips per TEU per year would continue to decrease slightly to 2.5 by 1988 (from 2.84 in 1978).

It is interesting to remark that in March 1978 SRI had submitted a much more pessimistic forecast to the members of the panel and it was accepted by most experts as being reasonable with the only exception of two more optimistic experts. However, the unprecedented increase in container population in 1977 and 1978 and a renewed optimism about prospects of future growth of world trade have reversed the earlier point of view to the present one with an average rate of growth about twice as large.

\subsubsection{World international general, liner and containerised cargo 1979-1988}

Table 8 shows projections of international general, liner and containerised cargo to 1988 . In making these projections, the following assumptions were made :

- Liner cargo will grow at slightly higher rate than general cargo since it is made up largely of manufactured products which, unlike the demand for semi-finished products, respond somewhat more rapidly to changes in economic activity.

- Containerised cargo is based on projected container traffic and a projected proportion of full containers. A factor of 8.4 metric tons per full TEU was used in converting to containerised tonnage.

From a statistical viewpoint, the bounds indicated in the Table represent an approximately $80 \%$ confidence interval.

The growth rate of general cargo traffic is projected between $4.5 \%$ and $8.5 \%$ with the expected rate of growth closer to the low value than the high value, probably of the order of 5 to 6 per cent.

Liner cargo growth rates will range from $5.3 \%$ (low) to $9.3 \%$ (high). The low and high projections for liner cargo are based on estimates of the historical relationship between liner and general cargo.

b 1973-1978. 
Table 8

Projections of world international general, liner, and containerised cargo

\begin{tabular}{|c|c|c|c|c|c|c|}
\hline \multirow[b]{2}{*}{ Year } & \multicolumn{2}{|c|}{$\begin{array}{c}\text { General } \\
\text { Cargo }\end{array}$} & \multicolumn{2}{|c|}{$\begin{array}{l}\text { Liner } \\
\text { Cargo }\end{array}$} & \multicolumn{2}{|c|}{$\begin{array}{c}\text { Containerised } \\
\text { Cargo }\end{array}$} \\
\hline & Low & High & Low & High & Low & High \\
\hline 1979 & 920 & 992 & 297 & 320 & 84 & 94 \\
\hline 1980 & 962 & 1,077 & 314 & 351 & 89 & 106 \\
\hline 1981 & 1,005 & 1,168 & 330 & 383 & 94 & 116 \\
\hline 1982 & 1,050 & 1,268 & 346 & 418 & 98 & 128 \\
\hline 1983 & 1,098 & 1,375 & 366 & 458 & 104 & 140 \\
\hline 1984 & 1,147 & 1,492 & 385 & 501 & 109 & 155 \\
\hline 1985 & 1,199 & 1,619 & 405 & 547 & 114 & 170 \\
\hline 1986 & 1,253 & 1,757 & 427 & 599 & 120 & 187 \\
\hline 1987 & 1,309 & 1,906 & 449 & 654 & 125 & 204 \\
\hline 1988 & 1,368 & 2,068 & 473 & 715 & 131 & 222 \\
\hline $\begin{array}{l}\text { Projected } \\
\text { Growth }\end{array}$ & & & & & & \\
\hline Rate (\%) & 4.5 & 8.5 & 5.3 & 9.3 & 5.0 & 10.0 \\
\hline $\begin{array}{l}\text { Historical } \\
\text { Growth } \\
\text { Rate }(\%)\end{array}$ & & & & & & \\
\hline
\end{tabular}

Containerised cargo is expected to exhibit a growth rate between $5.0 \%$ and $10.0 \%$ per year during the ten year period. These projections correspond to :

- projected container traffic divided by 4 ;

- estimates of full container moves ;

- 8.4 metric tons per full container move ;

- likelihood of increasing competition/overtonnaging.

It was assumed that full container moves would decrease slightly to $70 \%$ in 1988 , compared to $79 \%$ in 1978 and $86 \%$ in 1973. This assumed decrease results from :

- increasing trade with developing countries;

- increasing trade imbalances (i.e., the Middle East).

It should be noted that, as in the cases for container traffic and container population, the high rate of growth for containerised traffic is less than the historical rate of growth. It is expected to definitely slow down.

It should further be noted that the low and high rates of growth projected for containerised cargo bracket those for liner cargo. The reasons for this are :

- uncertainty as to when and to what extent the less developed countries will containerise ;

- uncertainty as to the extent to which commodities hitherto considered containerisable will be containerised. 
Expert opinion is that the rate of growth of containerised cargo will be closer to the low, rather than to the high, value $(6-7 \%$ rather than $7-8 \%)$.

\subsection{Relevant trends in the evolution of containerisation and containerised trade}

Beyond the figures showing the rapid expansion of container transport as a whole, there are several trends indicating changes in the structure of the container population and in its patterns of utilisation.

2.3.1 Changes in the structure of the container population

\section{(a) Container types}

The container population according to type is very stable. At the end of 1978 the distribution by type is approximately as follows (in \% of total TEU) :

$\begin{array}{lr}\text { Dry van containers } & 85 \% \\ \text { Refrigerated (Reefers) } & 6 \% \\ \text { Tank containers } & 0.5 \% \\ \text { Other types } & 8.5 \%\end{array}$

The vast majority of all containers are therefore of the dry van type. The proportion of dry vans has always increased regularly, if slowly, and a further increase of 2 or 3 percentage points can be expected by 1988. Refrigerated units and other types, on the other hand, are on slow but steady relative decline. The only type increasing significantly faster than the average is the tank container but it still represents a very small proportion of the total.

\section{(b) Container specifications as to size and strength}

Containers can be classified into 20 foot and 40 foot length categories by assimilating the few containers of odd lengths to the closest category $(10,24$ and 27 foot containers into the 20 foot category and 35 foot containers into the 40 foot category). The now odd lengths which were selected by some of the pioneers of containerisation will diseappear only slowly as it is difficult for these companies to progressively adopt the more conventional lengths and too costly to renew entirely their inventory. On the other hand, it is difficult to imagine that new lengths will be introduced although some requests have been made to this effect ( 45 foot containers).

Twenty foot and assimilated containers represent more than two thirds of the total number of units but only $60 \%$ of the total TEU capacity. There is a slight tendency toward a relatively larger number of $\mathbf{2 0}$ foot containers in the future.

Height specifications are moving rapidly toward a standard size of $8^{\prime} 6^{\prime \prime}$. Ninety per cent of the 40 foot containers and $40 \%$ of the 20 foot containers are already $8^{\prime} 6^{\prime \prime}$ high. The rest of the 20 foot containers are $8^{\prime}$ high but are being replaced almost exclusively by $8^{\prime} 6^{\prime \prime}$ units (the only snag is that $8^{\prime} 6^{\prime \prime}$ is too high for TOFC transport along the U.S. East Coast and in some regions of Europe).

More and more containers are designed to meet the very stringent ISO strength standards. Many of the new 20 foot containers are designed for the higher 24 tons gross weight limit. 


\section{(c) Construction materials}

Enormous progress has been made since the early days in the development and selection of construction materials, caulking compounds, protective coatings, etc. Three combinations are presently in use :

1. all steel containers (i.e. steel frame and cladding);

2. light alloy (aluminium) clading on steel or steel/light alloy frame ;

3. GRP/plywood cladding on steel frame.

Three-quarters of the 20 foot containers and a small half of the 40 foot containers are of the first type. Only few containers, 6 to $7 \%$, are of the third type.

Although the light alloy clad containers have many operational advantages over the all steel containers (lower weight, longer life, lower maintenance), a large price differential favours the all steel unit. A larger fraction of all steel units is therefore expected in the future.

(d) Ownership

Sixty per cent of all containers (measured in TEU) belong to shipping companies, $39 \%$ to leasing companies and only $1 \%$ to shippers. The leasing companies have played an increasingly important role in a period of uncertainty where many steamship lines prefer to own an inventory of containers corresponding to their minimum expected level of activity and lease the additional requirements.

Most leasing companies are presently based in North America (82\% of total leased inventory) where they own $67 \%$ of the container population. They concentrate on the most standard types of containers such as the dry van 20 foot all steel unit.

It is expected that by $19882 / 3$ of all containers and probably a larger fraction of the most basic types will be controlled by leasing companies.

\section{(e) Scrappage and age distribution of the population}

Thus far, relatively few containers have had to be replaced. Estimates are of about 40,000 TEU up to 1976 and perhaps 25,000 in 1977 and 35,000 in 1978. A significant proportion of containers that had to be replaced were either lost or damaged beyond repair. There is therefore very little experience available on ageing containers.

Only one out of six containers is more than 9 years old and one in two is less than 4 years old. Most of the very early containers which had not been designed for the marine environment have had to be replaced after a few years but there are still a few properly designed 20 year old containers in use today.

Most experts believe that the concept of useful life of a container should be analysed separately for all steel units and for light alloy units. Given the present technology, it is likely that the all steel units rust beyond economic repair within 10 to 15 years, the latest models being on the high side. On the other hand, units with special steel or light alloy frames and alloy claddings have not yet a known useful life but it can be expected to be more than 20 years ${ }^{4}$. GRP/ply clad units have a definitely short life, 7 to 10 years as they are not easily repairable.

4 Some companies do the first major refurbishing of containers of this type only when they are 15 to 20 years old and thus expect many more years of useful life out of these containers. 
These judgements have important consequences for the forecasting of new container demand. For example, assuming a 12 year life for all steel units, more than 20 years for alloy clad units and 10 years for GRP/ply clad units as well as taking into account the need to replace each year a small fraction of the inventory because of losses or catastrophic accidents, the likely forecast for new boxes is calculated in Table 9.

The figures in Table 9 are highly uncertain for two reasons : they combine the uncertainties of yearly differences of the forecast population and the uncertainties associated with the assumptions about the economic life of the various types of containers. As a result, an $80 \%$ confidence interval around the 510,000 TEU likely demand for 1984 could go from as low as 300,000 and as high as 750,000 . According to the likely assumption of Table 9 , the average age of containers in the total population would increase slowly from about 4 years now to 6 years in 1988 with all steel units being 5 years old on average and light alloy clad units being 8 years old on average.

Table 9

\section{Demand for new containers}

\begin{tabular}{lccc} 
Year & $\begin{array}{c}\text { Additional } \\
\text { Containers }\end{array}$ & $\begin{array}{c}\text { Replacement } \\
\text { Containers }\end{array}$ & $\begin{array}{c}\text { Total New } \\
\text { Demand }\end{array}$ \\
\cline { 2 - 2 } \begin{tabular}{cccc} 
Demann \\
\cline { 2 - 3 } 1979
\end{tabular} & 250 & 70 & 320 \\
1980 & 260 & 100 & 360 \\
1981 & 260 & 110 & 370 \\
1983 & 290 & 120 & 410 \\
1984 & 310 & 140 & 450 \\
1985 & 340 & 170 & 510 \\
1986 & 360 & 180 & 540 \\
1987 & 390 & 180 & 570 \\
1988 & 410 & 180 & 590 \\
& 430 & 200 & 630
\end{tabular}

\subsubsection{Trends in the evolution of containerised trade}

The patterns of containerised trade will evolve markedly over the next ten years for a number of different but often closely inter-related reasons. The major factors in the experts' opinion are as follows :

- Development of traffic to emerging countries (Middle East, South America, West and East Africa, Indian Sub-continent, South East Asia) as increase of traffic to new routes toward New Zealand and South Africa. This has multiple effects, the first one being a lengthening of the deep sea routes and therefore a proportionally greater demand for new containerships. Also the new routes will tend to be oriented North-South and therefore will cross a greater variety of climatic zones than the main east-west routes. 
- A second aspect of container trade with emerging countries will be the expected lower quality of equipment and terminal facilities as well as lower adequacy of transportation in the hinterland. Insufficient port facilities may necessitate a more extensive short sea feeder service.

- A third aspect of containerised trade with emerging countries is that a larger fraction of the trade will consist of foodstuffs and other perishable commodities inherently susceptible to spoilage. The trade may also be difficult to balance thus forcing carriers to seek marginally containerisable commodities.

- Relative increase of door to door service - many economic advantages result from a door to door service including the reduction of some types of risks such as theft, pilferage and non-delivery. However, door to door service means a greater development of inland containerised transport, more handlings of the container and waiting periods in inland depots. In particular, it is believed that a larger number of shippers will use containers as temporary warehousing. The main effect is an expected decrease of average container round trips per year from 2.85 today to around 2.5 in 1988. Also the exposure of containers and cargo to environmental hazards will be modified.

- Increased share in the transport of consumer and perishable goods - it is expected that technical problems such as sweating and condensation will be progressively resolved and that a greater number of consumer commodities and perishable goods which are today not economically containerisable because of the risks involved, will be adequately transported by containers in the 1980s. Such a trend would increase the average value of goods transported by containers.

Other expected changes in containerised trade patterns may be due to:

- the extension of land bridges, particularly Trans-siberian and Trans-Caucasian, as well as from the Gulf of Mexico Coast to the West Coast ;

- the development of alternative methods of transport, particularly with lesser developed countries, such as roll-on-roll-off ships and sea barge carriers (L.A.S.H. and SEABEE) ;

- the increase in size and performance and correspondingly costs of modern containerships. Combined with an increase in the average value of goods carried in a container, it is easy to see that modern containerships represent enormous values at risk in a single unity (for example, the total value of a 3,000 TEU modern containership can be evaluated at $\$ 70$ million for the ship, $\$ 12$ million for the containers and anywhere between $\$ 50$ to $\$ 150$ million and even more depending on the main commodities being shipped. The total value of the loaded ship may therefore well exceed $\$ 200$ million).

\section{Evaluation of economic risks associated with containerisation}

\subsection{Risks to containers and equipments}

Physical risks to containers and equipments are considered first, along with their indirect business consequences. Risks to cargo and other container operators' liabilities are considered separately in Section 3.2. 
Equipments other than containers represent the majority of investments in containerisation. Fully cellular containerships of the third generation have a cost per slot about five times larger than the average cost of a new container and the average container to slot ratio is in the neighbourhood of 3 to 1 . Investments in port facilities, particularly in lifting equipments, are also considerable. A modern double action dock side crane may cost more than a million dollars. However, we have chosen to concentrate our attention on the container box itself for several reasons :

- Containerships would form a highly specialised subject worth studying separately. There are many types of ships, each with their own potential risks. The actual loss experience is very sparse as fortunately very few major accidents have been recorded. On the other hand, minor damages to ships are not significant and not easy to distinguish from normal wear and tear.

- Handling equipments form also a vast subject; there are many types of cranes, straddle carriers and fork lift trucks and generalisations would be difficult. Again damages are fortunately rare except in the case of straddle carriers which have been involved in a number of accidents some of which have resulted in injuries and even loss of life.

\subsubsection{Total container risks and indirect damages}

\section{(a) Present risks}

Total container risks and consequential losses in 1978 are estimated at $\$ 400 \mathrm{~m}$ of which $77 \%$ are direct repair costs, $5 \%$ are losses and $18 \%$ are business opportunity losses due to unavailability of the containers. Only about half of these risks are presently insured.

This corresponds to approximate repair costs of $\$ 140$ per TEU per year, a loss in business opportunities of $\$ 32$ (time of repair is approximately 8 days but disruption of services has consequences beyond the time lost) and $\$ 10$ for loss of container. These figures vary according to the type of container. Aluminium clad container necessitate more frequent but less expensive repairs than steel containers; $40^{\prime}$ containers average only $\$ 250$ of repairs per year or $\$ 125$ per TEU whereas $20^{\prime}$ units average $\$ 150$ repair costs per year.

\section{(b) Future growth}

The following factors should nearly quadruple the total amount of container risks over the next ten years :

- growth of container population ;

- increase in average cost of repairs ;

- displacement of trade route causing greater exposure ;

- ageing container population and new safety standards;

- larger proportion of steel containers.

The increase in risks is estimated to be about proportional to the growth of the container population ( $+145 \%$ between 1978 and 1988) although containers will be used less efficiently than today (more rapid growth of container population than of container traffic). Indeed, empty containers are felt to be exposed to different but equally important risks than full containers : empty containers are often manipulated 
more casually than full containers ; they may be hit by other containers and equipments ; they may be blown away by heavy winds when stored in exposed areas.

Repair costs have risen sharply over the past few years and are expected to continue to go up in real terms at 1 to $2 \%$ per year for a cumulative effect of about $+16 \%$ by 1988 . The main causes of this increase are the greater use of special materials (special steels, caulking compounds, etc.) in the construction of containers and the rising costs of skilled labour.

Many container operators are concerned about traffic congestion and insufficient or inadequate equipment in many terminals particularly in some less developed countries. There are many instances where because containerisation is the most efficient method of transport between two marine terminals, containers are being pushed to secondary marine or inland terminals which are not fully equipped to receive them. Likewise, many consignees are being compelled to receive goods in containers although they do not have adequate equipment to handle these containers. As a result, the levels of risks on some secondary trade routes are estimated to be several times larger than on fully equipped and efficient routes. With the rapid development of secondary routes the frequency of accidents necessitating repairs is estimated to increase by $14 \%$ over the coming decade.

Older containers have been suspected of being more vulnerable than new containers. This was difficult to prove as long as rapid technological improvements in container construction was taking place and numbers of old containers of a given type were small. Some of the oldest and most experienced container operators are just beginning to see the proof : older containers appear to be more prone to leakages because of weakening of cladding or poorly fitting doors. These effects should show more clearly over the next 10 years during which the average age of the container population will increase by $50 \%$. At the same time quality standards are becoming stricter (particularly as a consequence of the new international Convention on Safe Containers) which will require more frequent and extensive repairs. In total the combined effect of age and stricter quality standards will push up total repair costs by $10 \%$ over the next 10 year.

Steel containers which are preferred to aluminium clad containers by many leasing companies (especially $20^{\prime}$ containers) are more costly to repair than their light alloys counterparts. A small increase in repair costs, $+5 \%$, by 1988 , is therefore expected for this reason.

As a result of all these changes, total container damages and loans together with indirect business opportunity losses are expected to increase to $\$ 1.5$ billion per year by 1988 , of which $77 \%$ or $\$ 1.5$ b will be direct repair costs, $4 \%$ losses and $19 \%$ indirect losses.

\section{(c) Frequency and magnitude}

The average repair cost per TEU per year will be about $\$ 215$ made up of 1.2 repairs at $\$ 180$ each (up from about one $\$ 140$ repair per year in 1978). Repair frequency will be slightly higher for light alloy clad containers than for steel containers but costs per repair will remain significantly higher for the latter. Repair per TEU on $40^{\prime}$ containers will remain slightly less than for $20^{\prime}$ containers. 
The maximum amount of losses is limited to the value of the container. New 20' dry van containers cost in the neighbourhood of $\$ 2,500$ for all steel units and $\$ 5,500$ for light alloy units of average quality. Special containers such as reefers can of course be much more expensive. A modern $40^{\prime}$ reefer can fetch $\$ 20,000$. The value of used containers decrease rapidly with age : it is about halved in 4 years for an all steel unit. Aluminium clad containers depreciate more slowly. Complete losses of containers rarely happen in isolation (except with hijacking but many hijacked containers are recovered). Complete losses are usually caused by major accidents to the carrier, e.g. ship sunk, fire, derailment. The sinking of a large containership could lead to the simultaneous loss of up to 3,000 containers. So far only much smaller ships have sunk with a few hundred containers only.

\section{(d) Uncertainties}

The major sources of uncertainties about total container damages are those lactors which affect the growth of the container population : economic growth, trade restrictive practices and regulation, development of new containerised routes. There are however two other factors which may change substantially the level of risks without affecting directly the trade volume; these are the evolution of maintenance standards and the displacement of trade routes.

The point was made repeatedly that there is an enormous gap between the very limited risks to containers on fully equipped routes and the high risks to which they are exposed in some poorly equipped terminals or when they are transported by inadequate means. These risks will increase as containerised transport becomes more disseminated with more door-to-door service which means a lesser importance of deep sea traffic and more feeder services and inland transport. Interestingly, the development of door-to-door services is almost unanimously considered as a means of reducing risks to cargo but at the same time it increases the risks to the container.

There is no absolute distinction between repair and maintenance, nor between accidental damages and normal wear and tear. The present cost of maintenance is about half the cost of repairs. Stricter quality standards will increase the costs of both maintenance and repair. The international Convention on Safe Containers is thought of having a potentially great influence on maintenance and repair standards (more so than on container design and construction which generally are already satisfactory). Some container operators may also go beyond the required standards for commercial purposes. Insurers can also play an active role by raising the awareness of their clients about the importance of inspecting and possibly rejecting containers when they are delivered to them. An insurance premium discount given to shippers using only containers of a certified quality could make more immediately visible the benefits of such policies.

\subsubsection{Classification of container risks}

\section{(a) Method of classification}

To gain insight into the origin and extent of container damages and losses, three forms of classification have been explored : by location (i.e. mode of transport), by type (nature of damage) and by cause.

Of these three forms the classification by type is the most reliable. The experts had many statistics to rely upon in making their assessments. The classification by 
location is not as simple as it might first appear because all containers are not inspected yet on a systematic basis at various points along the intermodal transport chain. Lessors in particular, except for the largest who have agents across the world, find it difficult to monitor the status of their boxes and many repairs are done by the combined transport operator or the shipper who leases the box at the time. Finally causes of damages do not seem to have been systematically analysed yet; this classification is therefore given with the warning that it only reflects the best judgment of the persons interviewed.

(b) Container damages and losses by location

Many experts were aware of an earlier report sponsored by the U.S. Department of Commerce (Cushing et al., 1975) which reported the following categories of hazards :

$\begin{array}{lr}\text { Handling in marine terminals } & 45 \% \\ \text { Cargo Stowage } & 25 \% \\ \text { Railroad } & 15 \% \\ \text { Highway } & 10 \% \\ \text { Sea } & 5 \%\end{array}$

These proportions were seen as being still valid today with perhaps a larger share attributable to terminal handling. We attempted however to suppress the category "Cargo Stowage" which is a cause of damage and not a location as such. The detrimental consequences of poor cargo stowage were deemed to take place mostly during terminal handling and at sea. The hazards of road transport were also felt to become higher especially with road transport in lesser developed countries. The distribution of risks according to location by 1988 was finally expected as follows :

\begin{tabular}{ll} 
Terminals including marine, \\
$\quad$ inland and warehouses \\
Road & $60 \%$ \\
Rail & $15 \%$ \\
Sea & $15 \%$ \\
Air & $10 \%$ \\
\hline
\end{tabular}

This clearly points out the importance of transshipment in terminals as a major hazard to containers.

\section{(c) Container damages by type}

The roof is by far the most vulnerable element in both steel clad and aluminium clad containers. Aluminium roofs are especially fragile. Misalignments of lifting equipment often causes aluminium roofs to be punctured; additional protection is being added near the roof corners on modern containers. Steel roofs are most robust when new but are easily weakened by rust if not properly maintained. New roof designs facilitate drainage of water from the roof.

Other vulnerable parts of a container are :

- the skin exposed to denting and scratching;

- the doors or end walls which on early models have proved to be insufficiently resistant to lateral or longitudinal forces when cargo is loose inside a container (many new containers meet higher than required standards for end wall strengths); 
- the floor which is too often damaged by stowing equipment (fork lift trucks) or improper stowage of heavy equipment.

Other types of damages are mainly structural and take place when a container is handled with improper equipment and consequently subject to unusual stresses.

The distribution of container damages by types is expected to be :

$\begin{array}{ll}\text { Roof } & 30 \% \\ \text { Sides } & 15 \% \\ \text { Doors and end walls } & 15 \% \\ \text { Floor } & 15 \% \\ \text { Other } & 25 \%\end{array}$

(d) Container damages and losses by cause

The categorisation of container damages by cause unfortunately points to less than purely accidental causes. Rather, most damages are caused by inadequate equipments, improper handling or careless operations. Rough handling, defined in a broad sense for all terminal handlings, accounts for more than half of the damages and improper cargo stowage for about one quarter. Such judgments are of course subjective as many damages can be attributed to either rough handling, poor stowage of cargo or excessive stresses during transport. This classification clearly indicates however that there is little to be gained in damage reduction by reducing transport stresses or building stronger boxes. Most of the damages are the natural consequence of time saving or cost saving policies. The principal issue is therefore whether shippers and operators are conscious of the possible damages and if so whether they have the right incentives to take these damages into account when making economic decisions.

The classification of damages and losses according to cause is :

$\begin{array}{lr}\begin{array}{l}\text { Rough handling } \\ \text { Poor stowage of cargo }\end{array} & 50 \% \\ \quad \text { and lashing of container } & 25 \% \\ \begin{array}{l}\text { Excessive transport stresses } \\ \text { including adverse weather }\end{array} & \\ \begin{array}{l}\text { conditions } \\ \text { Accident to carrier }\end{array} & 10 \% \\ \begin{array}{l}\text { Other including structural } \\ \text { weaknesses }\end{array} & 10 \%\end{array}$

\subsection{Risks to cargo and indirect damages}

The panel members were familiar with some of the claims paid figures over the past four years, but stressed that these figures give only a partial and biased view of the totality of losses and damages to cargo and other indirect damages such as delays and consequential losses. Indeed many damages are not insured or only insured within strict limits and among damages covered the ratio of claims paid to claim laid vary according to the nature of the damages. Educated estimates were therefore given but they remain highly subjective in many instances.

Attention was concentrated on cargo losses damages and delays and their business consequences and not on loss of life and bodily injury. This is for three reasons : first the experts were unanimous in stating that containerisation compared to more 
traditional methods had reduced these last two risks; second, only a fraction of the remaining risks can be directly linked to the container; third, most experts did not feel at ease in assigning an economic value to the loss of a human life.

The only two categories of injuries which are specific to containers and have been mentioned many times are :

- injuries resulting from corner twist locks dropping from the bottom of containers when they are lifted;

- traffic type accidents on the quayside often caused by negligent manoeuvering of mobile lifting equipment such as straddle carriers and forklift trucks.

\subsubsection{Total cargo risks and indirect damages}

\section{(a) Present risks}

Total claims paid in 1978 for cargo risks are estimated at about $\$ 250 \mathrm{~m}$ but this is an underestimate of all cargo risks and indirect damages.

- According to various international conventions (which are in the process of being modified and uniformised, see for example the new UNCITRAL rules) insurance coverage is limited to maximum values per unit of cargo and subject to deductibles.

- Claims paid represent 65 to $85 \%$ of claims laid depending on circumstances, in particular on the nature and the estimated location (mode of transport) of damages.

- Many types of damages, in particular delays and consequential losses, are inadequately covered by insurance. For example, only one insurance company offers coverage for strikes although container traffic, at least in its infancy, has been the subject of many longshoremen disputes.

A fair estimate of all cargo risks and indirect damages must by necessity be subjective. Experts estimated that claims paid represented on average only $75 \%$ of damages incurred in the categories protected by insurance and that another $20 \%$ of damages (mostly delays and consequential losses) were not covered today. In other words the estimate of total cargo risks and indirect damages in 1978 was put at $\$ 400 \mathrm{~m}(1.20 \times 250 / 0.75)$. Coincidentally, this is exactly the same figure as that estimated for container risks.

\section{(b) Future growth}

The major factors of change between 1978 and 1988 are :

- increase in container cargo traffic;

- displacement of trade routes ;

- progress in packaging, storage and handling;

- increase in average value of cargo ;

- increase in consequential losses.

The most significant container cargo growth factor was deemed to be the increase in container traffic (number of movements of containers in and out of marine terminals in millions of TEU) rather than the increase in containerised cargo weight or the increase in container population. Indeed the increase in cargo weight does not reflect the lengthening of each cycle extending well beyond marine terminals into the hinterland. On the other hand, the increase in container population corresponds to a 
large extent to more unbalanced trade and therefore to the movement of many empty containers as well as to a less efficient use of containers in general. The increase in container traffic over the next ten years is estimated at $+115 \%$.

There appears to be a considerable difference in cargo risks among trade routes with relatively low risks on well established fully containerised deep sea routes between industrialised countries and much higher risks on new route to lesser developed countries. Explanation of this phenomenon are manifold but can be categorised into two large classes of factors : superior equipment and operating procedures on the well established routes and greater exposure to environmental conditions and vulnerability of goods traded with lesser developed countries (agricultural products in particular).

The equipment issue is also a concern in the development of inland door-to-door services as many shippers and receivers will have only limited lifting capabilities. As a whole, the development of containerised trade toward lesser developed countries as well as the further penetration of containers inland will create a relative increase in risks of $+20 \%$ over the coming decade despite the general improvements that can be expected in packaging, storage and handling of container cargo.

- The average value of container cargo is expected to increase slightly in real terms as this cargo has an above average labour and energy content. A total increase of $8 \%$ over the next ten years was assumed.

- Many of the indirect damages associated with containerised transport will grow rapidly. This is a direct consequence of the qualities of speed, low cost and reliability of container transport which will create greater dependence of commerce and industry upon this form of transport. Already many industrial companies have specialised production and reduced their inventories because of the speed and dependability of container transport. Any disruption in the transport system is therefore bound to have greater repercussions. The proportion of indirect business losses, currently poorly insured, was assumed to increase from about $17 \%$ to $23 \%$ over the next ten years.

The total economic losses from cargo and indirect losses are expected to amount to about $\$ 1.2$ billion by 1988 of which $77 \%$ would be direct losses and $23 \%$ indirect losses. This is a tripling of losses over a ten year period.

\section{(c) Uncertainties}

The major sources of uncertainties affecting total cargo risks are obviously those factors which would affect the total volume of trade : overall pace of economic development and possibilities of trade restrictions. Some other less conspicuous sources of uncertainties will however affect directly the cargo risks; these are :

- Container maintenance standards - especially as containers get older the quality of maintenance will have an important bearing on the degree of protection of the cargo inside the box. There is a trade off between higher costs of maintenance and lower risk to cargo which will be quite sensitive to regulations, rule establishing liabilities and pricing of insurance.

- Packaging and storage - one of the major advantages of container transport has been to reduce the cost of packaging. Many shippers however may have gone too far. Containers in fact have been known to have special packaging problems, for example, to control and reduce the effects of condensation. Packaging is also 
designed nowadays with the more general objective of facilitating production, storage and distribution. Many consumer goods (apparels, tableware, foodstuffs) are shipped in packages that are ready for display on store shelves. The multiple objectives of having a low cost and protective package fit for display creates uncertainties as to the level of protection that will be achieved.

- Custom clearance, safety control and pick-up procedures - a large proportion of cargo risks, in particular risks of theft, are faced when the container is lying at a terminal rather than when it is beeing carried. Risks are limited when the terminal area is under strict control and containers are removed rapidly. However, there are many terminals where control is insufficient or insufficiently secure (a computerised system for recording container locations and movements must be made particularly secure to avoid revealing useful information to robbers), where custom clearance procedure still sacrifice safety and where cargo is not rapidly reclaimed.

- Warehousing - with the development of door-to-door services, many shippers and receivers have found it convenient to keep containers for temporary warehousing. If this practice extends, as it may given the relatively low daily cost of container leasing, a new source of risks will emerge.

\subsubsection{Classification of cargo risks}

\section{(a) Method of classification}

Cargo risks can be and are classified in many different ways. In fact each combined transport operator, shipper, insurer has developed his own definition or interpretation of risk categories and a uniform presentation of historical data as well as forecasts is difficult to achieve. With the objective of clarifying the discussion and gaining as much insight as possible into future trends and feasible remedies, we have adopted three distinct forms of classification :

- by location ;

- by type or nature of risks ;

- by cause ;

and for each classification the number of classes has been kept to a minimum. A classification by type of damage is the most important objective and the easiest to accomplish ; most of the classifications in use refer to the type of risk. A classification by location has very simple and clearly defined categories, however the locations where cargo damage take place are usually not known with great confidence except in a few obvious cases. There are of course correlations between types and locations of risks but many damages are concealed until final delivery and could have taken place anywhere along the multimodal transport chain. Finally a classification by cause is probably the most insightful but also the most controversial form of classification. We have endeavoured to trace causes back to the level of human and therefore correctable action.

The following estimates are based on the opinion of the panel members and the detailed analysis of claim statistics from a number of carriers. There were no strong disagreements among the experts but a general impression that there could be a large difference among carriers, trade routes and commodities. The following estimates should therefore be regarded as soft and general. Any attempt to compare or apply them to a specific and limited situation should clearly recognise the particularities of that situation. 


\section{(b) Cargo damages and losses by location}

The concentration of cargo risks in terminal areas is not quite as dramatic as for container risks. Nonetheless, the hazards of handling and the risks of theft make the terminal areas the most dangerous places for containerised cargo. Current estimates are that about one-third to $40 \%$ of cargo risks are incurred in terminal areas and that this percentage will increase to about $45 \%$ by 1988 due to the construction of a large number of inland terminals. Obvious dangers are caused by lack of security. Many inland terminals for example are not fenced off or as in the case of rail terminals have fences on all sides except along the railroad. Air terminals are not immune to dangers. In fact many are not as well organised as marine terminals in terms of control systems and protection of cargo. In many air terminals high value cargo is left unattended and unprotected from the weather.

The sea leg of a multimodal transport presents relatively more risk to the cargo than to the container because of many environmental hazards such as sea water, fresh water, extremes of temperature and condensation which affect the cargo more than the box. This is especially true for containers stowed on deck. Unfortunately, it is often not possible to guarantee that a container with sensitive goods will be stowed in the hull rather than on deck because of a multiplicity of operating constraints. Modern containerships with a higher free board and a lower number of containers stacked on deck show a definite improvement. Many small feeder vessels on the other hand offer very little protection to containers carried on their decks. As the number of such services is deemed to increase the risks will grow proportionally. Estimates of risks at sea show therefore an improvement for deep sea transport (better safety, smaller relative volume) and a larger proportion of risks for feeder services (increasing relative volume and no quality improvement as a whole).

Rail and road transport is rather improving as some of the teething problems are being resolved (for example, cushioning of wagons to diminish vibrations and shunting shocks and better suspension of trailers to avoid overturning). Road will remain more risky than rail because it is more prone to accidents, poor handling and theft. Road transport risks are expected to be particularly high in lesser developed countries. The security problems posed by road transport are expected to improve (two drivers, constant surveillance, alarm systems).

Containerised transport by air is rapidly becoming intermodal with the new generation of jumbo jets (especially the 747 combi). The total tonnage of containerised goods transported by air will however still be small in 1988 compared to the other modes of transport and the exposure is minimal (the major problem seems to be temperature control). Nonetheless, due to the high average value of the goods carried and their often vulnerable nature (flowers, apparels, fruits) the risks will not be negligible.

The distribution of cargo risks by mode of transport in 1988 is finally estimated as follows 5 :

5 These percentages should not be interpreted as representing the relative hazards per container, rather they also reflect the relative importance of container transport in each mode. 
Table 10

$\begin{array}{lr}\text { Terminals } & 45 \% \\ \text { Sea - deep } & 12 \% \\ \text { Road - feeder services } & 15 \% \\ \text { Rail } & 12 \% \\ \text { Air } & 15 \% \\ & 1 \%\end{array}$

(c) Cargo damages, losses and delays by type

Types of damages, losses and delays have been grouped into three major categories: losses, physico-chemical damages and mechanical damages. Losses, which include delays (temporary loss), can be associated mainly to malicious acts (theft, pilferage, short loading...) or lack of control (non delivery, mysterious disappearance). Mechanical damages is a clearly defined category which cover all damages from shocks or excessive pressures (breakage, denting, bending, etc.). The third category is a bit of a catch all ; it corresponds to all non mechanical deteriorations of the goods. There are two major sub-categories : damages caused by water (fresh, sea and condensation) and others (mostly temperature control problems).

The estimated distribution of losses among these categories today and in $\mathbf{1 9 8 8}$ is as follows :

Table 11

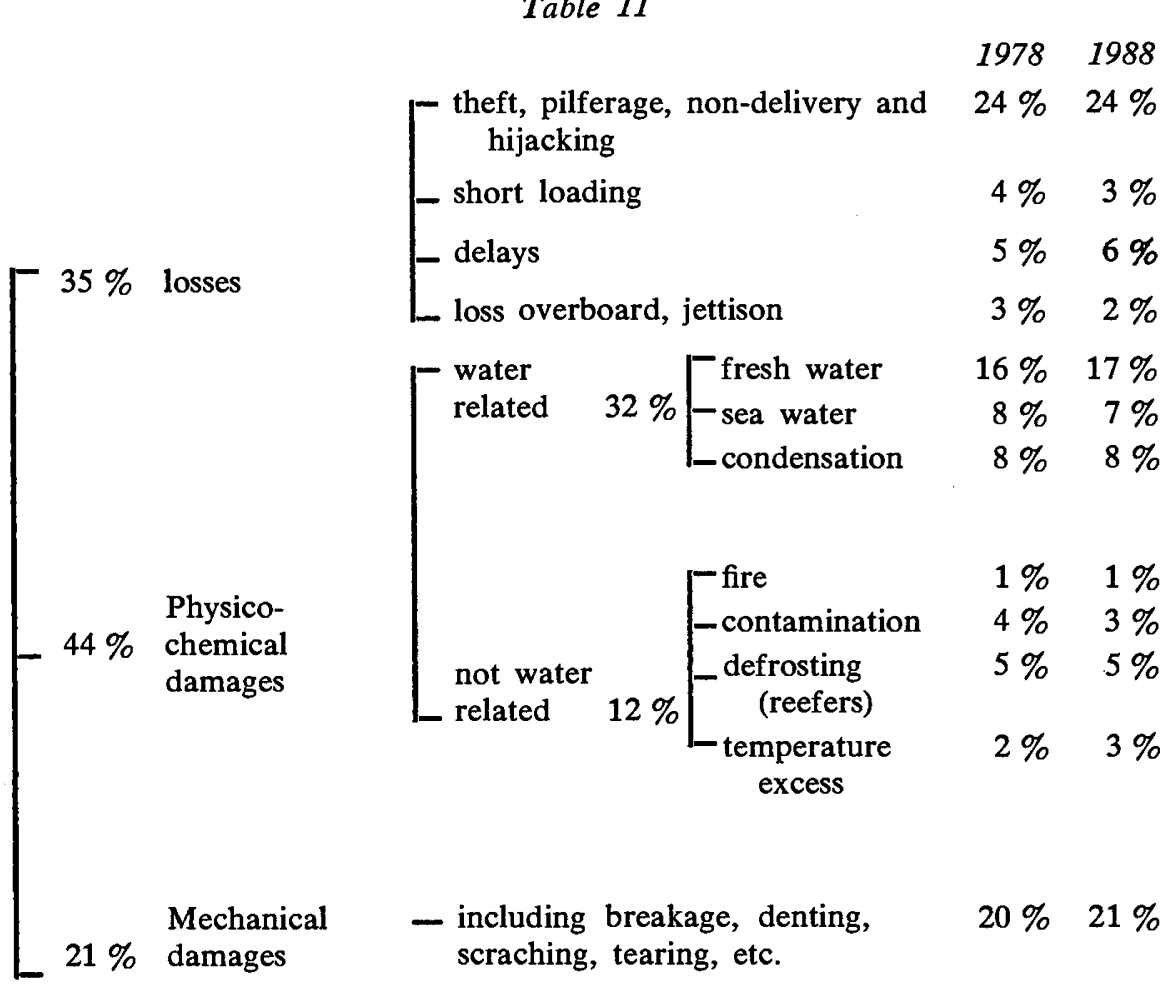


There are remarkably little changes in relative importance among the three major categories over the coming decade. A more detailed analysis shows however a few significant trends within each category. On the increase are :

- Delays which take a greater importance both in frequency (transport to LDCs and inland transport) and in magnitude (greater disruptive effects of delays in production systems depending on reliable transportation).

- Water damages of the fresh water and condensation types. Sea water damages are slightly receding because of ship modernisation and lesser importance of the sea leg. Fresh water damages are increasing mostly because of the older container population (more subject to leaks) and condensation damages increase because of the larger amount of hygroscopic goods which shall be carried across different climatic zones. (Progress in preventing condensation is slow and often costly.)

- Temperature control problems (other than refrigeration problems with reefers), are also on the increase because of the same reason as above and of the greater role played by air transport.

- Mechanical damages are expected to increase modestly because of the development of container transport further inland and also on route with inferior equipment and facilities. This will more than counteract the effects of technological improvements in handling equipments, better packaging and stowing practice and better training of personnel on the most efficient routes.

On the decrease (always in relative terms) are :

- short loading;

- hijacking :

- loss overboard;

- fire;

- sea water damages ;

- contamination.

Such improvements are expected mostly from technological developments in equipments and packaging, better control systems and a relative reduction of deep sea voyages.

An attempt has been made to clarify the various cargo risks by magnitude and frequency. Several choices were feasible for example in terms of commodities or modes of transport. It was felt to be most meaningful in terms of types of damages because of the good correlation that exists among type of damages and average losses per event, the relative simplicity of this classification compared to say commodities and the fact that several analysis have already been carried out along these lines.

There remains however two difficulties. First the definition of one event of loss is highly conventional. One could consider rightly that the Hamburg floods or that the fire on the Sea Witch were single loss events causing each several million dollar losses. On the other hand, from the point of view of the shipper or the insurer having just one container on the Sea Witch or in Hamburg at the time of the disaster, the magnitude of the event was limited to the value of the goods in that container. Liability rules tend even to limit each event to still smaller units. In analysing losses from a macro-economic point of view one should therefore keep in mind the enormous 
concentration of value on a single modern container ship which can reach several hundreds of millions of dollars and can be all subject to a single catastrophy. This represents a much higher concentration of risks than experienced with conventional means of transportation (one modern containership can be said to replace 4 to 6 conventional vessels).

From a micro-economic point of view the risks of course are much less concentrated. If one takes the extreme view that each claim laid corresponds to a single risk the average amounts of damages and their frequencies are estimated as follows :

Table 12

Type

Theft

Pilferage, non-delivery

Short loading

Delay

Loss overboard

Fresh water

Sea water

Condensation

Fire

Contamination

Defrosting

Temperature excess

Mechanical

All Categories $a$

\begin{tabular}{c}
$\begin{array}{c}\text { Average } \\
\text { Amount } \\
(\$)\end{array}$ \\
\hline 360 \\
160 \\
520 \\
400 \\
4,000 \\
300 \\
500 \\
220 \\
4,000 \\
340 \\
2,500 \\
1,500 \\
260 \\
\hline 300 \\
\hline
\end{tabular}

Frequency

(per 1000 TEU

per year)

57

130

10

25

0.5

95

25

65

1

15

3

3

140

570

There are of course large variations around the average for each type of claim and the average is different for various operators and various modes of transport. They tend to be lower for road transport, average for rail and sea and above average for air transport.

(d) Cargo damages and losses by cause

The most controversial of all classifications is by cause if one attempts to define causes in a more fundamental way than by stating what happened, where and when. Ultimately the notion of cause calls for a judgement about what could and should be corrected in order to prevent or reduce the losses. We have tried for simplicity to limit the causes to a few broad categories :

$a$ The frequency of claims for all categories is obtained by adding the frequencies of the various categories. The average amount of claims, namely 300 dollars, is equal to the sum of the average amounts of the various categories weighted by their relevant frequencies. 
- malicious acts cover naturally theft, pilferage, hijacking and some of the shortages non-deliveries and other "mysterious disappearance of goods". It also covers some other losses which happen as a consequence of malicious acts, e.g. delays ;

- bad packaging, staffing and storage are either involuntary (lack of information) or planned (cost and time savings). Multiple objectives must therefore be reconciled in order to arrive at rational recommendations;

- faulty container should be seen as either faulty design (rare) or faulty maintenance (it exists) or more often faulty inspection procedures which leads to using an improper container or a container in improper conditions. Again this is sometimes planned because other commercial considerations must be taken into account but it causes understandable irritation to insurers ;

- rough handling is self explanatory ;

- other causes are numerous but as a whole represent only a small fraction of all causes. Many of them are accidents to the carrier (e.g. derailment) or acts of God (e.g. typhoon).

The distribution of cargo risks in 1988 according to the above causes is :

Table 13

$\begin{array}{ll}\text { Malicious acts } & 27 \% \\ \begin{array}{l}\text { Bad packaging, stuffing } \\ \quad \text { and stowage }\end{array} & 23 \% \\ \begin{array}{l}\text { Faulty containers } \\ \text { Rough handling }\end{array} & 20 \% \\ \begin{array}{l}\text { Others (including accidents } \\ \text { to carrier and acts of God) }\end{array} & 12 \%\end{array}$

The high contribution of malicious acts may surprise some readers. It is of course an ethical and legal problem as well as a commercial one. In fact from a purely economical point of view it is a redistribution of wealth accompanied by disrupting effects. For reasons of simplicity we have not tried to estimate and to deduct the resale value of stolen property from this category of losses.

Interestingly one can remark that a large proportion of cargo damages could be prevented by better procedures rather than or in conjunction with better equipments. These include :

- security procedures ;

- better training of personnel for packaging, stuffing and handling ;

- better inspections and control procedures.

\section{(e) Problem commodities}

In the course of discussions and from questionnaires a number of commodities have been mentioned as potentially risky commodities. Table 14 gives a summary list of the main commodities (by order of decreasing importance) with their expected degree of containerisation by 1988 and the major types of risks involved. 


\section{Table 14}

\section{Commodity Code ${ }^{a}$}

01 Meat and meat preparations

76 Telecommunications and sound recording and reproducing equipment

77 Electrical machinery, apparatus and appliances

05 Vegetable and Fruits

88 Photographic apparatus, optical goods, watches and clocks

87 Professional scientific and controlling instruments

12 Tobacco

54 Medicinal and pharm. products

75 Office machines and EDP equip.

64 Paper, Paper Board, Pulp

21 Hides, skins and fur skins
Percentage

Containerised

by 1988

80

90

85

80

90

85

85

85

85

50

85

\begin{tabular}{lll}
\multicolumn{1}{c}{ Risk } & & Location \\
\cline { 1 - 1 } Spoilage & & Deep sea \\
Faulty & & Terminal \\
Refriger. & &
\end{tabular}

Hijack

Terminal

Water

Deep Sea

Water

Deep Sea

Pilferage

Terminal

Spoilage

Temp.

ALL

ALL

Pilferage

Terminal

Water

Deep Sea

Pilferage Terminal

Breakage Sea

Pilferage Terminal

Water Sea

Spoliage Packaging

Pilferage Terminal

Breakage Handling

Pilferage Terminal

Water Deep Sea

Water

Deep Sea

Pilferage Terminal

Temp.

\section{Reflections on risk prevention and control}

It is hoped that this study will start filling a gap for all the parties concerned with intermodal transport by containers. We discovered that many combined operators, lessors, and shippers have started collecting information and analysing the issue of risks associated with container transport. Unfortunately these researches are fragmented and considering the vast difference in experience among operators, trade routes and for various commodities, it is very difficult to generalise.

a Standard International Trade Classification (Revision 2). 
The current study brings admittedly more opinions than facts but should be useful in describing the anticipated scope of the issue of container transport risks and the areas deserving the greatest attention. Experts have predicted that over the next ten years containerised transport, whichever way it is measured, is likely to more than double because it corresponds to significant saving in cost and time over the older conventional methods of transport. The total risks associated with container transport, however will more than triple. This is due mainly to the displacement of traffic from the major deep sea routes towards new routes to emerging areas and toward inland transportation with more and more door to door services. The loss experience on fully equipped routes is improving continuously (much better in general than by alternative means of transport) but the situation of poorly equipped or organised routes is far different. The success of the container may be pushing its use into areas or commodities where it is not economically advantageous - when all the risks are properly taken into account.

The total risks, direct and indirect, of container transport (excluding handling equipment such as containerships and other transport equipment) are estimated to reach $\$ 2.7$ billion by 1988 , of which $\$ 1.5$ billion can be linked to container damages and losses. A distribution of these risks in percentage terms by cause and location shows approximately the following figures (rounded to the closest percentage point).

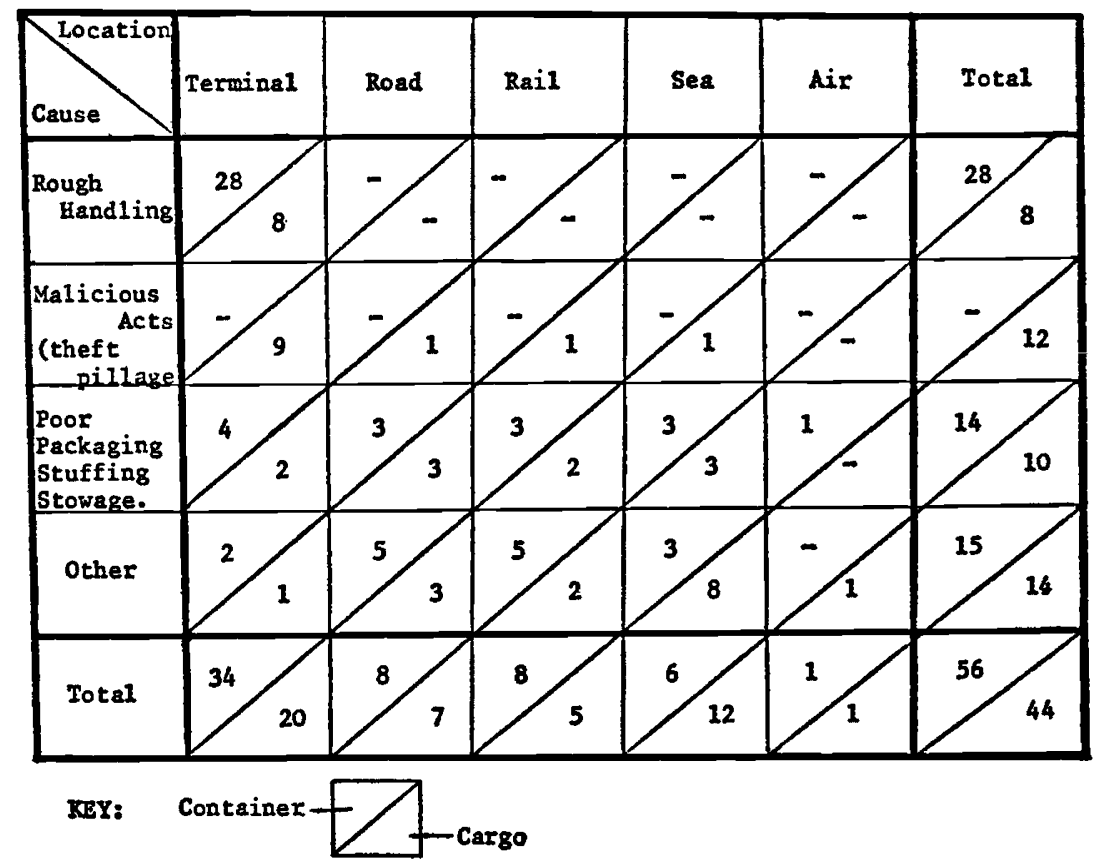

Although these estimates should be considered as "soft" and actual loss experience varies greatly according to specific circumstances, two trends are clear:

- The preponderance of terminals (not only marine but also inland terminals, depots and warehouses) as the location of risk. 
- The overwhelming role played by negligence, human errors and human frailties as a cause of damages and losses.

These findings indicate that it would be most important to review from a systems point of view the economic tradeoffs which have led to the development of present policies and practices regarding packaging, handling, safety and control. It is likely that each party dealing with container transport seeks to act in his best interests but it is not certain that :

- All parties are sufficiently aware of the risks involved.

- The rules establishing the liabilities of the various parties give the right incentive to achieve the best results in a macroeconomic sense.

Examples of specific research which would lead to a better, more systematic view of containerised transport and consequently to a more rational risk management are :

- A comparison of facilities, operating procedures and loss experience of terminals attention should be given not only to the major marine terminal facilities where handling is normally efficient, but also to the growing number of inland terminals (rail and road depots and air terminals) where equipment and handling procedures are often of lower standard, as well as to smaller, often congested, port facilities in lesser developed countries.

- A review and analysis of inspection and repair facilities with a view to assessing economically viable rules for inspection, repair and maintenance.

- A review and analysis of terminal security with emphasis on physical protection, sealing procedures, control systems and documentation, customs clearance and inspection procedures.

- A comparative study of the costs and risks associated with various forms of packaging and methods of transport for specific trade route and commodities. This study should look beyond the purely transport risks and into production and distribution costs in general.

As containerisation continues to develop rapidly the gap will widen between applications where containers bring a clear economic improvement and those where the advantages of containerisation are at best marginal or even detrimental when all consequences including risks are taken into account. Multinational conventions and codes of practice can help steer containerisation in the right direction. Economic incentives reflecting the risks being faced, as for example through a judicious assignment of liabilities and proper insurance pricing, will also have an important role to play in leading to an economically sound development of container transport.

\section{Freight Container 6}

\section{APPENDIX A}

\section{Glossary}

An article of transport equipment :

- of permanent character and accordingly strong enough to be suitable for repeated use ;

6 Recommendation R668, The Technical Committee 104 of the ISO (International Standards Association). 
- specially designed to facilitate the carriage of goods by one or more modes of transport without intermediate reloading ;

- fitted with devices permitting its ready handling, particularly its transfer from one mode of transport to another ;

- so designed to be easy to fill and empty ;

- having an internal volume of $1 \mathrm{~m}^{3}$ or more.

Types of Containers

- Dry Van

A freight container similar in size to a highway trailer body. Generally speaking, the term is applied to containers with dimensions 20 feet or more in length, 8 feet in width and 8 feet or more in height. It can carry a variety of packaged, bagged or cartoned or palletised goods. It is stuffed and unstuffed by hand or forklifts through end doors or side doors. It is specified as weatherproof. Some types are hermetically closed, others are ventilated.

- Refrigerated (Reefer)

A van type container equipped with a refrigeration unit which can bring the ambient temperature generally to $-30^{\circ} \mathrm{C}$, sometimes to $-40^{\circ} \mathrm{C}$. During sea voyages, reefers are usually plugged into the containership power supply. Many reefers are $40^{\prime}$ aluminium-clad containers.

- Open Top

Similar to dry van but with a removable canvas on top instead of a fixed roof, thus allowing loading and unloading by overhead crane.

- Flat/Platform

The structure is limited to a frame with/without fixed end walls. They are used for the transport of heavy machinery or other bulky objects needing little protection.

- Tank

A steel or aluminium tank in a container frame for the transport of liquids or fine powders.

ISO

International Standardisation Organisation. One Committee of ISO has set dimension and strength standards for containers which are widely adopted by manufacturers.

Container Chassis

A semi-trailer frame with single or tandem axles fitted with standardised corner fittings for receiving and securing a van container of matching size so that it can be moved over the road in the same fashion as a highway trailer.

\section{Piggyback}

The transportation of cargo in highway trailers or containers (either directly or on a chassis) or their empty returns, making use of the physical facilities of rail and motor carriers.

Container on a Flatcar (COFC)

A piggyback movement employing a container only. 
Trailer-on-Flatcar (TOFC) chassis

A piggyback movement employing a highway trailer or a van container on a Lift-On-Lift-Off (LO/LO)

Containership designed for vertical lifting and lowering of containers into and out of holds equipped with guides, by means of shore cranes or on-board deck gantry cranes. There are many types, including :

- Full Containerships ;

- Limited Containerships ;

- Part Containerships ;

- Convertible Containerships ;

- Container / Pallet ships ;

- Container / Railcar Carriers ;

- Container / Barge Carriers.

Roll-On-Roll-Off (RO/RO) or "Huckepack"

Ships designed to be able to load and discharge wheeled vehicles and containers horizontally by means of ramps leading ashore and from deck to deck. Some ships carry all their containers on chassis; other ships load, stow and discharge containers using straddle carriers or forklift trucks.

\section{Full Container Load (FCL)}

A container load of goods, for which the merchant (Shipper/Receiver) bears all responsibility for packing and unpacking. A full container load will normally travel unopened from origin to destination.

Less than Container Load (LCL)

A container load of goods usually formed by grouping the goods of several merchants in a container depot and under the responsibility of the carrier for packing and unpacking.

\section{Feeder Service}

A transport service between a major container port and smaller ports which are not equipped to receive and discharge modern container vessels. The service is therefore carried out by comparatively small ships usually taking the containers on deck as regular cargo.

\section{Lighter Aboard Ship (LASH) / Sea Barge Carrier (SEABEE)}

Ships designed to load and unload specially designed lighters usually carrying from 300 to 500 tons of cargo.

Combined Transport Operator (CTO)

A freight forwarder or carrier who offers a comprehensive door-to-door intermodal container service. 


\section{Bill of Lading}

A document of title to goods which may be consigned to a single party or be negotiable. A bill of lading evidences a contract of carriage and acts as a receipt until the carrier delivers the goods against surrender of the document.

\section{Insured Bill of Lading}

Combined bill of lading and insurance certificate that has been offered on a mandatory basis by two British shipping consortia. The advantages and disadvantages of this solution have been actively debated.

Protection and Indemnisation Club (P\&I)

Club of carriers, sometimes large shippers, organised to provide liability coverage on a mutual basis to its members. P\&I Club rules limit this coverage to the sea-leg of a combined transport.

\section{Through Transit Club (TTC)}

A club founded by three major British P\&I clubs to provide a comprehensive range of coverages to its members on a mutual basis. Coverage is available for door-todoor activities and includes equipment used by container operators as well as containers.

\section{APPENDIX B \\ Containerised cargo losses statistics \\ from the International Union of Marine Insurance (IUMI)}

\section{The data}

Mr. A. E. Mann of the London Institute of Marine Underwriters has collected data on containerised cargo, damages and losses from various National Associations of the IUMI. The data are with respect to claims paid per year with a reporting threshold of $\$ 1,000$ until year $1975 / 76$ and of $\$ 2,000$ since. The data go back to $1971 / 72$ for a total 7 years now. Until $1975 / 76$ four sample countries only were represented but the sample is now much wider and therefore more representative. The reports forms sent to the Associations have evolved over the years; in particular, they have been greatly simplified in $1977 / 78$. However the results have been classified in the same format to facilitate comparisons from year to year.

Figure B-1 reproduces the main results ; the twelve charts represent the evolution of 12 major categories of losses both in relative frequency of claims and fraction of total paid claims for all claims above the reporting treshold.

In addition to the relative evolution of each category of losses shown in Figure B-1, Mr. A. E. Mann reports the following variations in total number and value of claims :

\begin{tabular}{lll} 
& $1976 / 77$ & $\frac{1977 / 78}{15}$ \\
\cline { 2 - 3 } number & $-6 \%$ & $+58 \%$ \\
total value & $+5 \%$ & $+66 \%$ \\
value per claim & $+12 \%$ & $+5 \%$
\end{tabular}


Figure B-1

Cargo losses statistics

$\%$ comparison by number and amount of separate categories
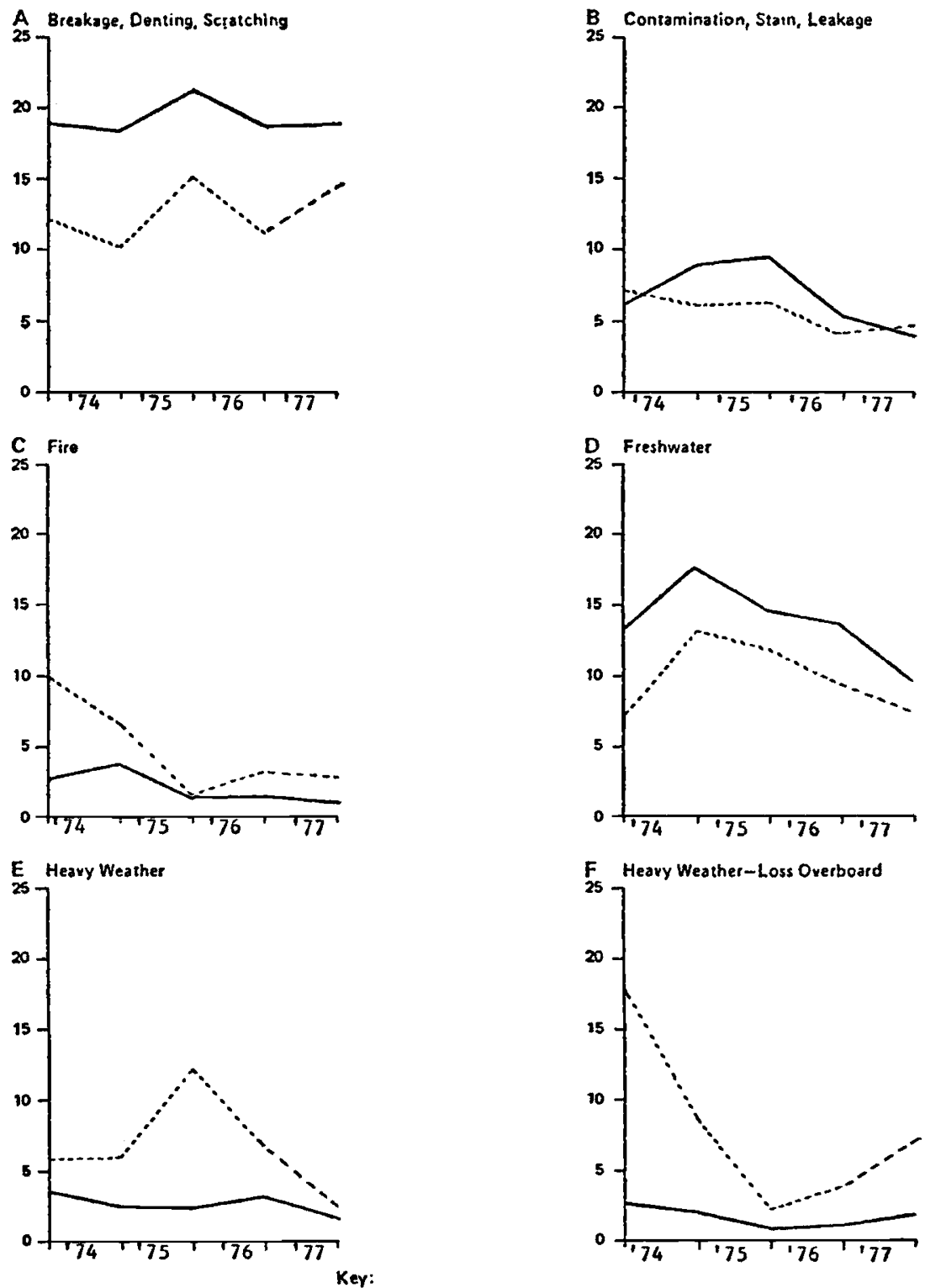

Number

Amount 
Figure B-1 continued

Cargo losses statistics
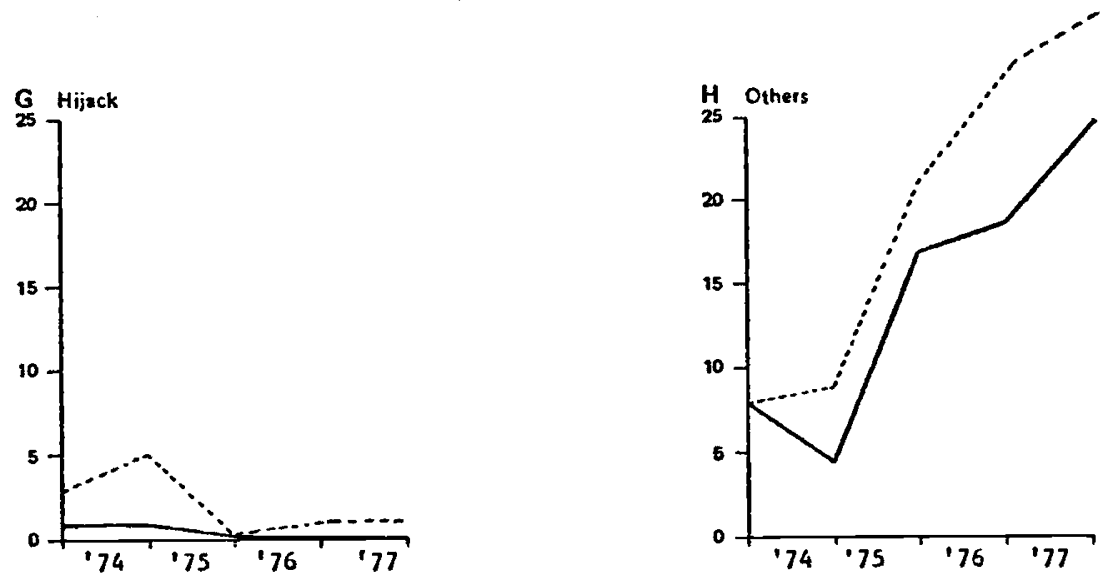

I Refrigeration Breakdown, Defrosting J Seawater
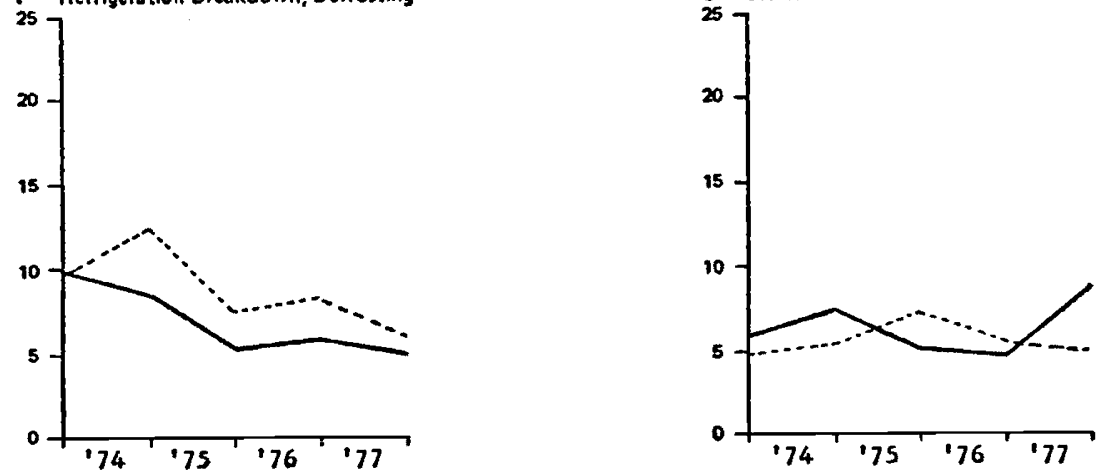

K sweat

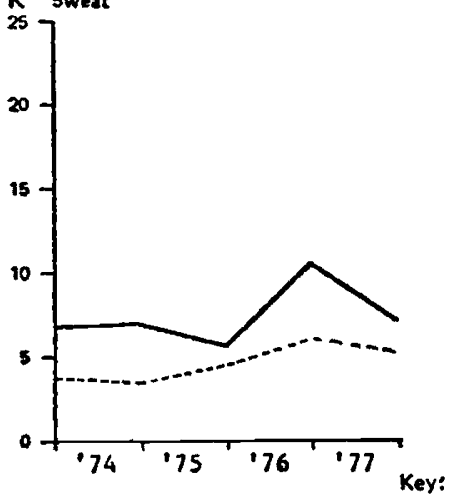

1 Theft, Pilferage, Non-delivery

25

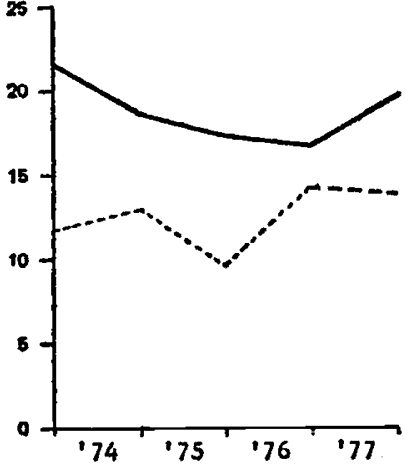

Number

Amount 


\section{Interpretation and discussion}

The above figures are quite unique in their scope and highly interesting to analyse but caution must be exercised in interpreting them.

The most dramatic result a priori is probably the $66 \%$ increase in total paid claims during the last year; a detailed analysis shows however that it does not necessarily indicate a large relative increase in container losses. Indeed several factors contribute to this increase : inflation of the dollar raising the value of all claims and bringing more claims above the reporting threshold; the rapid increase in container traffic from 1976 to 1978 ; the simplified reporting forms provided in $1977 / 78$ which may have enticed insurers to report more claims. Assuming for example a $12 \%$ inflation of the US dollar, $6 \%$ more claims reported because of the relatively lower reporting threshold, a $16 \%$ increase in container traffic and $20 \%$ more claims reported because of the simplified form one would arrive exactly at the $66 \%$ increase in total claims paid reported in $1977 / 78$.

The $58 \%$ increase in the number of claims reported is not a decisive indication of increasing losses either. According to the previous assumptions, one would expect an increase in number of $48 \%$ and in value per claim of about $12 \%$. The figures reported show instead a proportionally greater number of smaller claims. This effect must have taken place also during the previous year since despite an increase of the reporting level from $\$ 1,000$ to $\$ 2,000$ and the effect of inflation the average cost per claim increased only by $12 \%$.

One must therefore look beyond the total number of claims and claim values in order to discern whether the risks of container transport have increased significantly over the past two years. An interesting insight was provided by $\mathrm{Mr}$. Mann in a private communication when he indicated that the reports from the American Association in 1977/78 did not show significant changes over the previous year. This implies that reports from other Associations must average well above $60 \%$ increase in both number and values of claims. It is of course possible that the container traffic underwritten in the USA has not increased as rapidly as elsewhere in the world and that American underwriters were less sensitive than others to the simplification of the report form. Discounting the more than $60 \%$ difference in the evolution of risk in one year between the US and other countries because of these two factors leaves nonetheless a strong indication that the US experience is improving significantly compared to the rest of the world and probably also in absolute terms (i.e. in losses/TEU/year).

The curves reproduced in Figure $\mathrm{B} 1$ give a general indication of the relative evolution of various loss categories but this indication is blurred and may be even distorted by two factors :

- In the first place one must remember that the figures reported represent a sample of at most $20 \%$ in value of all claims paid and an even lower percentage in number of damages and losses incurred. Furthermore the claims reported are the largest. The number of claims in the sample is therefore subject to large statistical fluctuations. In addition some categories of damages are either over represented or under-represented. For example, it is likely that in categories such as hijacking, loss overboard and fire, average claims have high values and therefore most claims are reported whereas in categories such as breakage, fresh water damages and 
pilferage, average claims are well below $\$ 2,000$ and only a small fraction of the claims are reported.

- A second issue is the definition of the categories of losses themselves. In a desire of simplification a unique list of 27 types or causes of loss has been designed. However it is difficult to make the categories in such a list both exhaustive and mutually exclusive. This may explain why a larger number of losses are finding their way each year into the "Other" category which includes :

- rough handling ;

- rust ;

- bad packaging ;

- shortage ;

- rejection;

- road accident ;

- ship sunk ;

- cutting, chaffing, etc. ;

- and other.

Taking into account the two previous remarks makes some of the results shown in Figure B1 even more remarkable than they would appear at first :

- The four categories which register the highest claim values are : "Breakage, denting, scratching", "freshwater" and "theft, pilferage, non delivery" and "Others". The first three are made up of relatively small claims and are therefore probably under-represented. The fourth category is made up of several sub-categories which could be associated with the first three ; for example " rough handling", "bad packaging", "cutting, chaffing" and "road accident" could well be linked to "breakage", likewise " shortage" could well be linked to "theft, pilferage and non delivery" and " rust" to "water damages".

The first three categories mentioned have also a relatively low average loss per claim, they are therefore probably under-represented in the sample. All this points to their importance.

- On the other hand some categories that should be well represented in the sample because of their high average claim value such as "fire" and "hijack" show a significant reduction of risk over the past five years. This is also true but to a lesser extent for the categories "Heavy weather" and "Refrigeration breakdown".

\section{APPENDIX C The panel members}

The authors and the Geneva Association are deeply indebted to the panel members who gave freely of their time to answer the survey questionnaire, to discuss their opinions in the course of personal interviews and on many occasions to collect data and carry out research within their respective organisations in order to make more meaningful contributions to this study. While we are deeply indebted to all panel members, without whose contributions the study would not have been possible, the final responsibility for the synthesis of data and the conclusions drawn rests solely with the authors. 
Ms. Maureen F. ALLYN, Director Forecasting Sealand Service Inc., Edison, NJ

Mr. A. L. BROWN, Assistant to General Manager International Services, Southern Pacific Transportation Co., San Francisco, CA

Dott. Ing. L. COLAUTTI, General Manager, Porto di Trieste, Italy

Mr. Dennis C. DI SALVO, Vice President Operations, ITEL Container Division, San Francisco, CA

Mr. VAN DEN DOEL, Manager, Port of Rotterdam, Netherlands

Mr. T. A. FANTE, Assistant Vice President, Southern Pacific Transportation Co., San Francisco, CA

Mr. Ian FLETCHER, Security and Information Services, Thomas R. Miller \& Son, London, UK

Mr. David FOX, President, CTI - Container Transport International Inc., White Plains, NY

Mr. G. GIOVANNINI, Presidente, Italia Assicurazioni SpA, Milano, Italy

Mr. Leland GOREVIN, Manager Insurance, Matson Navigation Co., San Francisco, CA

Mr. Arthur J. GORMAN Jr., Director of Planning, ITEL Container Division, San Francisco, CA

Mr. Christopher D. HENRI, Technical Director, Marine Insurance Council of Australia, Melbourne

Mr. John B. HOVLAND, Marine Supervisor, Royal-Globe Insurance Co., San Francisco, CA

Mr. S. G. HOWARD, Chief Development Officer, Freightliners Ltd., London, UK

Mr. A. E. JENNER, General Manager, Intermodal Services, CP Rail, Montreal, Canada

Mr. Jay P. KAPLAN, Vice President Market Planning, ICS Inc., New York, NY

Mr. Niklas KIHLBOM, Managing Director, Atlantica Insurance Co., Gothenburg, Sweden

Mr. D. D. KIRBY, General Manager, British Railways Board, International Services Division, London, UK

Mr. Walter M. KRAMER, Assistant Vice President, American Institute of Marine Underwriters, New York, NY

Eng. Wilson M. LOUBRIEL, Executive Director, Port Authorities of Puerto Rico, Puerto Rico

Mr. Kenneth LUCK, Superintendent, Port of London Police, London, UK

Mr. A. E. MANN, London Institute of Marine Underwriters, London, UK

Mr. P. G. MODICA, Manager, International Intermodal Sales and Services, Santa Fe Railway Co., Chicago, Ill.

Mr. S. A. REED Jr., General Manager, Technical Services, Interway Corporation, New York, NY 
Mr. B. H. RUSHING, General Freight Claims Agent, Southern Pacific Transportation Co., San Francisco, CA

Dr. G. B. SACEO, Capo Servizio Lavoro Portuale, Porto di Genova, Genova, Italy

Herr Manfred SAMES, Vice President Marketing, Contrans GmbH, Hamburg, W. Germany

Mr. James A. SMITH, Executive Vice President, CTI - Container Transport International, White Plains, NY

Mr. Philip STEINBERG, President, Pacific Merchant Shipping Association, San Francisco, CA

Mr. Karl STEIS, Legal Department, CMB Antwerp, Belgium

Mr. Dennis TAYLOR, Claims Surveyor, Malcom Sheppard, Banstead, UK

Mr. J. TAYLOR, Chief Planner, The Melbourne Harbour Trust Commissioner, Australia

Mr. Edward K. TROWBRIDGE, Senior Executive Vice President, The Atlantic Companies, New York, NY

Mr. B. W. VINTNER, Claims Adjuster, South British Insurance Co. Ltd., London, UK

Mr. R. D. WURTZ, General Manager Container Equipment Maintenance, Matson Navigation Co., San Francisco, CA

Mr. Lloyd D. YATES, Director Research and Development, Matson Navigation Co., San Francisco, CA

\section{APPENDIX D}

\section{Short bibliography}

1. Containerisation and Marine Insurance (1972), Report by Advanced Study Group No. 196 of The Insurance Institute of London, 20 Aldermanbury, London EC2V7HY, UK.

2. Containerized Transport and Marine Insurance (1977), Münchener Rückversicherungs-Gesellschaft, D-800 München 40, Königinstrasse 107, Federal Republic of Germany.

3. Conteneurisation (édition annuelle), édité par les Services Lamy, 155 bis, rue Legendre, Paris $17^{\mathrm{e}}$, France.

4. The State of Containerization 1978, A Study by Transport 2000 presented by and on behalf of Flexi Van Corporation, 330 Madison Avenue, New York, N.Y. 10017

5. Containerisation in the 1980's (December 1978), Cargo System Research, 201/205 High Street, New Malden, Surrey, KT34BH, UK.

6. A Study of Intermodal Container Safety (1976), Cushing C., Kimball P., Higgins M. prepared for the US Coast Guard, Washington, DC.

7. "Container losses", by A. E. Mann, in Policy, pp. 30-31, November 1978, edited by the IUMI, Stadthausquai 5, Zurich 1, Switzerland. 